\title{
Nanocarbon-Enhanced 2D Photoelectrodes: A New Paradigm in Photoelectrochemical Water Splitting
}

Cite as

Nano-Micro Lett.

(2020) 13:24

Received: 28 July 2020

Accepted: 30 September 2020

Published online: 13 November 2020

(C) The Author(s) 2020

\section{HIGHLIGHTS}

- Layered integrated photoelectrodes for water splitting incorporating nanocarbon co-catalysts are systematically reviewed.

- The correlations between intrinsic structures, optimized configurations, and water splitting performances of layered integrated photoelectrodes are established and analyzed.

- Various synthetic strategies and assembling procedures are critically examined to enhance water splitting performance of layered integrated photoelectrodes.

- Current challenges and future directions for maximizing the efficiency of photoelectrochemical water splitting are outlined.

\begin{abstract}
Solar-driven photoelectrochemical (PEC) water splitting systems are highly promising for converting solar energy into clean and sustainable chemical energy. In such PEC systems, an integrated photoelectrode incorporates a light harvester for absorbing solar energy, an interlayer for transporting photogenerated charge carriers, and a co-catalyst for triggering redox reactions. Thus, understanding the correlations between the intrinsic structural properties and functions of the photoelectrodes is crucial. Here we critically examine various 2D layered photoanodes/photocathodes, including graphitic carbon nitrides,
\end{abstract}

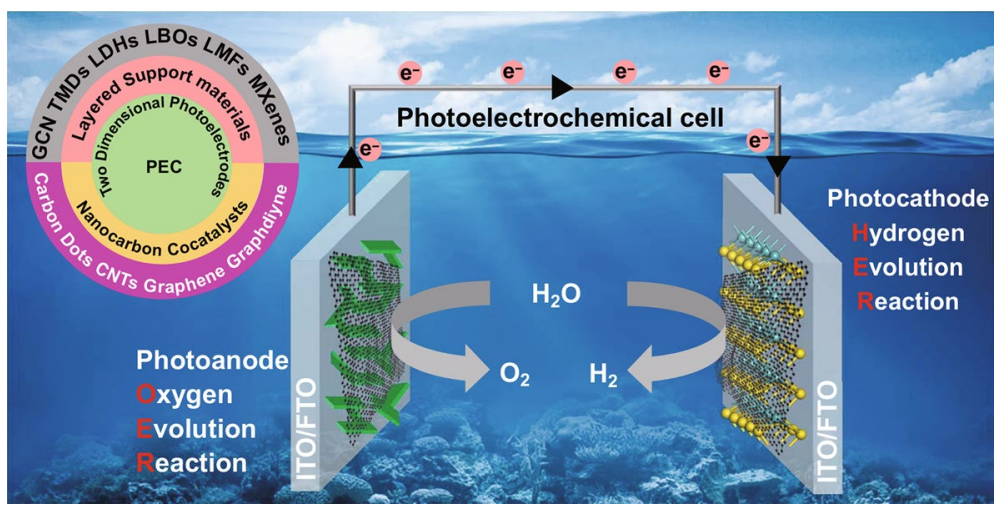
transition metal dichalcogenides, layered double hydroxides, layered bismuth oxyhalide nanosheets, and MXenes, combined with advanced nanocarbons (carbon dots, carbon nanotubes, graphene, and graphdiyne) as co-catalysts to assemble integrated photoelectrodes for oxygen evolution/hydrogen evolution reactions. The fundamental principles of PEC water splitting and physicochemical properties of photoelectrodes and the associated catalytic reactions are analyzed. Elaborate strategies for the assembly of 2D photoelectrodes with nanocarbons to enhance the PEC performances are introduced. The mechanisms of interplay of 2D photoelectrodes and nanocarbon co-catalysts are further discussed. The challenges and opportunities in the field are identified to guide future research for maximizing the conversion efficiency of PEC water splitting.

KEYWORDS Advanced nanocarbons; Co-catalysts; 2D layered structure; Integrated photoelectrodes; Photoelectrochemical water splitting

Jie Liu, liujiedut@hotmail.com; Yang Hou, yhou@zju.edu.cn

${ }^{1}$ Key Laboratory of Biomass Chemical Engineering of Ministry of Education, College of Chemical and Biological Engineering, Zhejiang University, Hangzhou 310012, People's Republic of China 


\section{Introduction}

Conversion of clean and renewable solar energy into storable chemical energy is a viable and sustainable approach to solving the grand challenges of exhaustible fossil fuels and environmental pollution. In 1972, it was reported that clean $\mathrm{H}_{2}$ energy can be produced from water splitting through a photoelectrochemical (PEC) cell with a $\mathrm{TiO}_{2}$ photoanode [1]. What is why combining heterogeneous photocatalysis with electrochemistry is a powerful strategy to achieve the efficient conversion of solar energy [2, 3]. In a typical PEC system, semiconductor-based photoelectrode is the key component, which captures solar light and promotes redox reactions, including water splitting $[4,5], \mathrm{CO}_{2}$ reduction $[6,7]$, and $\mathrm{N}_{2}$ fixation $[8,9]$.

Upon light irradiation, a semiconductor photoelectrode can be excited by the photons which possess equal or greater energy than its bandgap energy. As a result, photogenerated holes remain in the valence band, while photogenerated electrons are formed and separated within picoseconds, and then jump to the conduction band. The photoinduced holes and electrons are then rapidly transferred to the interface between the photoelectrode and the electrolyte, guided by the intrinsic energy band alignment and the applied electric field $[10,11]$. The photogenerated electrons trigger reduction reactions such as hydrogen evolution reaction (HER), $\mathrm{CO}_{2}$ reduction, and $\mathrm{N}_{2}$ fixation. The corresponding holes in turn take part in oxidation reactions such as the oxygen evolution reaction (OER) and organic pollutant degradation. Importantly, for large-scale applications of solar-driven water splitting, a PEC system is required to possess high energy conversion efficiency, high HER and OER reaction rates, long-term stability, operational safety, and low cost.

Up to now, although major efforts have been made to approach the expected targets, the achieved catalytic performance is still insufficient for practical applications.
Therefore, developing advanced high-performance energy materials, and obtaining deep insights into fundamental principles of photochemical conversion and electrocatalytic processes in PEC system are essential to fabricating highly efficient photoelectrodes for solar-driven water splitting [12].

Aiming at increasing the overall efficiency for PEC water splitting, advanced two-dimensional (2D) energy materials, including graphitic carbon nitrides (GCNs) [13], transition metal dichalcogenides (TMDs) [14], layered double hydroxides (LDHs) [15], layered bismuth oxyhalides (LBOs) [16], and MXenes [17], etc., have been developed in the past decades, as shown in Fig. 1. Compared with conventional semiconductor photoelectrodes that are usually limited by low accessibility of active sites, 2D layered photoelectrodes feature more active exposed edges and atomic defects, which are beneficial for the PEC water splitting. Experimental and theoretical results reveal that the ultrathin 2D geometry with reduced thickness can provide highly exposed surface area and abundant active atoms. Meanwhile, interior atoms could be brought closer to the surface in thinner atomic layers, thereby facilitating the contact between the catalysts and reactants [18], while more exposed active sites can be utilized for surface catalytic reactions. In addition, rich surface defects, unsaturated atoms, and/or active edges can be produced along with the formation of ultrathin layered structures. Therefore, designing ideal 2D layered photoelectrodes for achieving efficient light capture and charge separation, as well as fast reaction kinetics to increase the PEC water splitting activity, is on the agenda of the forefront research and development efforts.

It is well known that to achieve high-quality photoelectrodes, efficient electrocatalyst/co-catalyst is an inevitable component in a PEC system. Commonly, a proper electrocatalyst can be introduced into a PEC system as a co-catalyst to accelerate photoelectrocatalytic reactions as well

\footnotetext{
2 School of Chemistry and Environmental Engineering, Wuhan Institute of Technology, 206 Guanggu 1st Road, Wuhan 430205, People's Republic of China

3 Department of Environmental Science and Engineering, North China Electric Power University, 619 Yonghua N St, Baoding 071003, People's Republic of China

4 Institute of Zhejiang University - Quzhou, Quzhou 324000, People's Republic of China

5 Ningbo Research Institute, Zhejiang University, Hangzhou 315100, People's Republic of China

6 State Key Laboratory of Industrial Control Technology, College of Control Science and Engineering, Zhejiang University, Hangzhou 310012, People's Republic of China

7 School of Chemistry and Physics and Centre for Materials Science, Queensland University of Technology, Brisbane, QLD 4000, Australia
} 

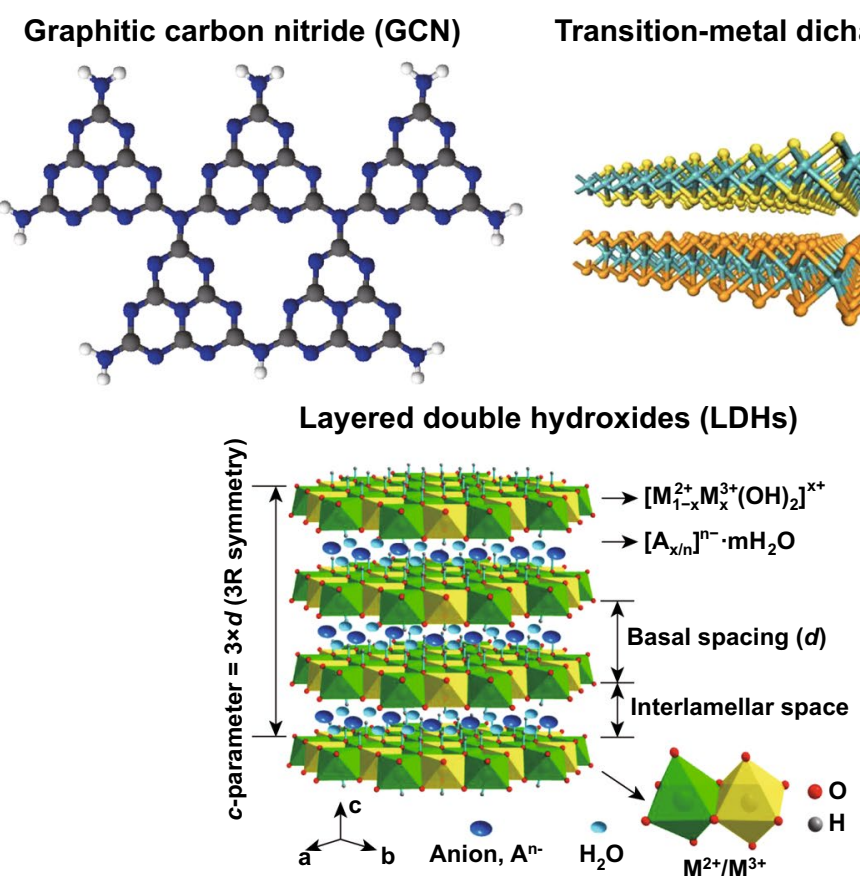

Transition-metal dichalcogenides (TMDs)

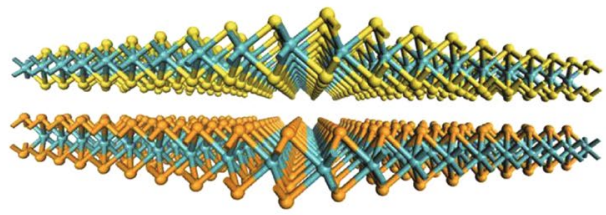

Layered Bismuth Oxyhalide (LBOs)

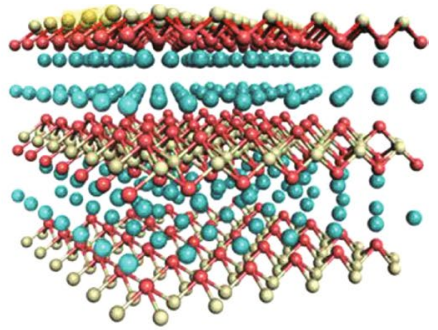

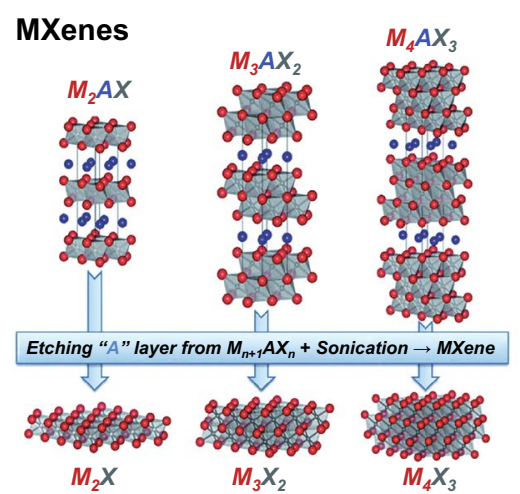

Fig. 1 Crystal structures of various 2D layered materials used in PEC solar energy conversion [172, 184-187]. Copyright 2017 and 2016 American Chemical Society, 2015 Royal Society of Chemistry, 2013 Springer Nature and 2017 MDPI (Basel, Switzerland)

as to improve photoinduced charge separation and transportation efficiency at the junctions/interfaces between co-catalyst and light harvesting semiconductor [19-21]. In the past decades, proton reduction co-catalysts (e.g., noble metals [22], metal sulfides [23], metal phosphides [24]), and oxidation co-catalysts (e.g., $\mathrm{IrO}_{x}$ [25], $\mathrm{CoO}_{x}$ [26], $\mathrm{Co}_{3}\left(\mathrm{PO}_{4}\right)_{2}$ [27], $\mathrm{CoCuO}_{x}$ [28], $\mathrm{WO}_{3}$ [29]) have been widely developed for water reduction and water oxidation reactions, respectively. Besides, the unique advantages of strong interfacial interactions between the supporting 2D photoelectrodes and electrocatalysts in an integrated photoelectrode and electrocatalyst system have been recognized [30].

As a class of multifunctional co-catalysts, nanocarbon materials have been widely studied and explored in the past two decades, owing to their high conductivity comparable to metals, which means that free electrons can rapidly move in the whole carbon material [31-34]. For instance, graphene and graphdiyne (GDY) are formed by a single-layer carbon with $s p^{2}$ bonds and mixture of $s p$ and $s p^{2}$ bonds, respectively. Both these materials possess high charge and mass transport ability [35-38]. Moreover, density functional theory (DFT) calculations reveal that the charge mobility of single-layer graphene and graphdiyne can reach up to $\sim 3 \times 10^{5}$ and $2 \times 10^{5} \mathrm{~cm}^{2} \mathrm{~V}^{-1} \mathrm{~s}^{-1}$, respectively, which infers the excellent electron transport behavior. Subsequently, a series of graphene- and graphdiyne-based electrocatalysts have been developed for HER and OER by means of combining with other host $2 \mathrm{D}$ photoelectrodes, including conventional metal oxides and abovementioned 2D GCNs, TMDs, or LDHs [39-42]. Apart from 2D graphene and graphdiyne, other carbon allotropes, such as carbon nanotubes (CNTs) and carbon dots (CDs), acting as 1D and $0 \mathrm{D}$ electron shuttles and collectors, have been utilized to modify 2D photoelectrodes. These integration strategies provide a viable opportunity to explore the $2 \mathrm{D}$ PEC systems for solar-driven water splitting in scientific research and engineering fields [43-46].

In this review, the fundamental principles of solar-driven PEC water splitting and critical physiochemical properties of 2D photoelectrode materials are introduced and discussed systematically. We critically analyze the current status of various integrated photoelectrodes made of $2 \mathrm{D}$ layered photoelectrodes as host materials, such as GCN, TMDs, LDHs, LBOs, and MXenes, and advanced nanocarbons, such as graphene, graphdiyne, CNTs, and CDs 
as co-catalysts to achieve highly efficient PEC water splitting. Finally, the critical challenges in this research field are identified to offer our perspective on maximizing the PEC conversion efficiencies of these 2D integrated photoelectrodes for water splitting.

\section{PEC Water Splitting System}

\subsection{Components of PEC System}

Commonly, a typical PEC water splitting system is comprised of at least two electrodes partitioned by using an ion exchange membrane, where the oxidation and reduction reactions can be carried out independently on the photoanode and the photocathode, respectively [47]. As presented in Fig. 2a, $n$-type semiconductor acting as a photoanode has the Fermi energy level above the potential of electrocatalytic water splitting, resulting in an upward band bending, upon semiconductor contacting with electrolyte. In contrast, the contact of a $p$-type semiconducting photocathode with electrolyte leads to a downward band bending [48, 49]. Once excited by incident light, host semiconductors are able to absorb photons with higher energies than the bandgap energies of semiconductors and produce photoinduced charge carriers. Subsequently, photogenerated charge carriers are separated at a timescale of picoseconds by built-in electric field $\left(E_{\text {in }}\right)$ in the depletion region, thus resulting in the formation of photopotential ( $V_{\mathrm{ph} 1}$ or $V_{\mathrm{ph} 2}$ ) as a driving force for electrocatalytic reactions [50].

Furthermore, owing to different functions of PEC systems, they can be configured with different electrodes and electrolytes for achieving efficient water splitting under light illumination. As shown in Fig. 2b, for a tandem PEC system, it is comprised of a photocathode and a photoanode in single PEC cell, in which both photoelectrodes are used and illuminated simultaneously, and the generated photoelectrons and holes are subsequently participated in the solar-driven overall water splitting [51].

When the photocathode and photoanode are excited by incident photons at the same time, two photopotentials are simultaneously formed and then drive the electrocatalytic redox reactions on the surface [52]. From the thermodynamic viewpoint, the total photoinduced potential $\left(V_{\mathrm{p}}\right)$ should be larger than the theoretical redox potential of overall water splitting $\left(E_{\mathrm{H} 2 \mathrm{O}}=1.23 \mathrm{~V}\right)$ as unavoidable kinetic overpotentials for $\operatorname{HER}\left(\eta_{\mathrm{R}}\right)$ and $\operatorname{OER}\left(\eta_{\mathrm{O}}\right)$ need to be overcome when photoelectrodes contact with electrolytes in a practical PEC system. Furthermore, considering the existence of various additional resistances, the potential loss $\left(\eta_{\text {other }}\right)$ across the two-electrode PEC system should be added. Since both photocathode and photoanode can contribute to $V_{\mathrm{p}}$, many candidate materials with the suitable bandgap energies are used to assemble a tandem PEC system for harvesting sunlight in a broad spectral range and producing strong photocurrent density, thus aiming to achieve high PEC water splitting efficiency.

In contrast, when only a photocathode or a photoanode is involved in a PEC system, a sufficiently high photoinduced potential of the photoelectrode needs to be produced to achieve the overall water splitting. Therefore, the host semiconductor photoelectrode is required to have a wide bandgap (Fig. 2b, c), which is detrimental to the sunlight absorption, thus leading to low photocurrent density and poor solar energy conversion efficiency. To solve this issue, external photosensitizers and co-catalysts need to be introduced and integrated with the wide-bandgap semiconductor to improve light absorption capacity and water splitting activity, respectively. In addition, narrowbandgap semiconductors (e.g., Si) can also be utilized to assemble an efficient photoelectrode by coupling with light absorber and co-catalyst together, as shown in Fig. 2d [53], where sufficiently high photoinduced potential can be produced for the overall water splitting. The charge exchange between photosystem II (PSII) and photoanode is enabled by the redox couple $\left(\mathrm{A}^{+} / \mathrm{A}^{*}\right)$ to contribute the electric circuit of PEC system $[54,55]$. As a typical example, Domen et al. took advantage of $\mathrm{Ru}(\mathrm{bpy}) \mathrm{S}_{3}^{2+3+}$ complex as a redox shuttle to increase the open-circuit potential in $n$-type $\mathrm{CdS}$ photoanode/Pt PEC system [56]. Here we note that the oneelectron redox reaction of Ru complex made a significant contribution to the high open-circuit potential and shortcircuit current under visible light irradiation, in comparison with the onset potential of direct water electrolysis. These findings are beneficial for enhancing both the hydrogen and oxygen evolution reactions.

\subsection{Material Requirements}

As is well known, the water splitting reaction in PEC system involves multi-step proton and electron transfer processes 


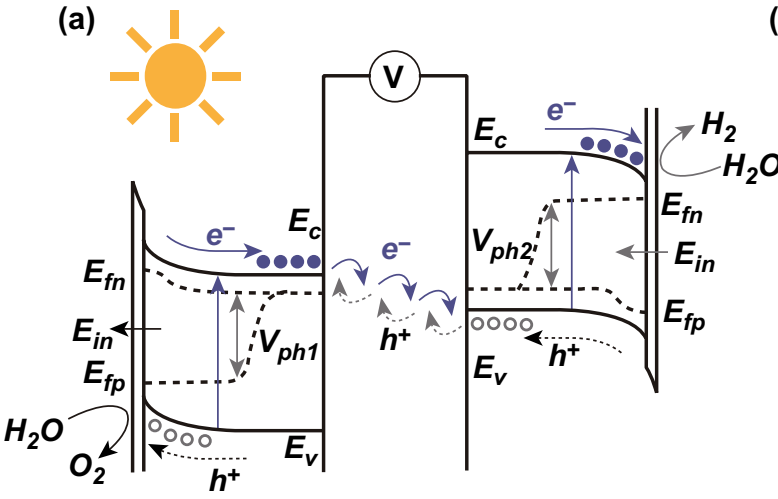

Photoanode

(c)

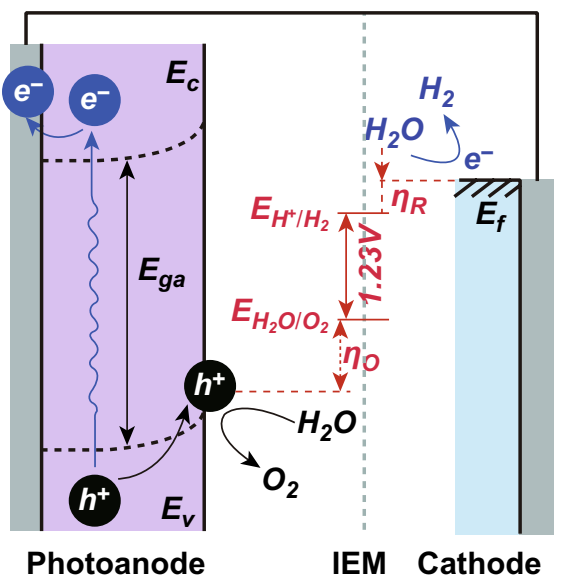

(b)

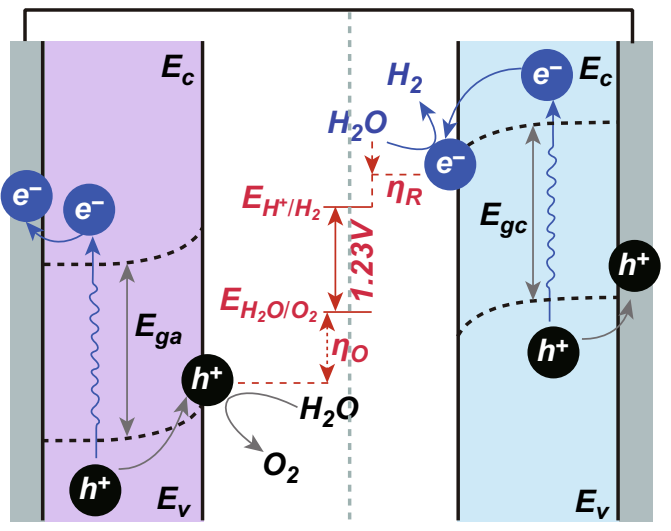

Photoanode (d)

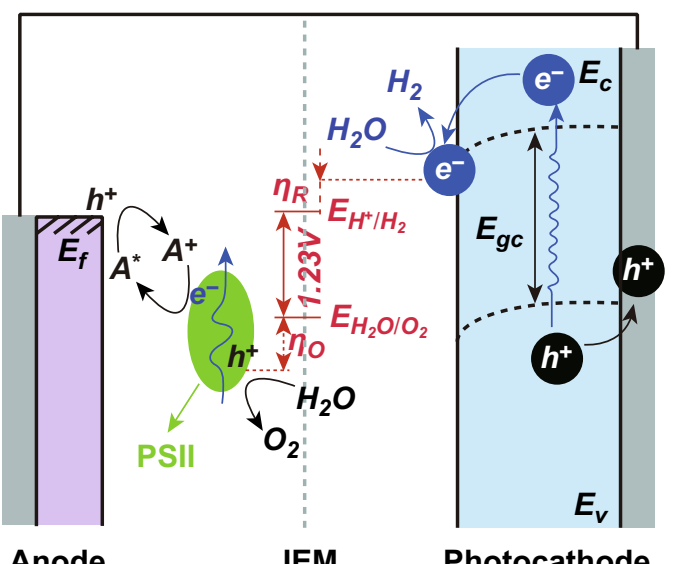

Fig. 2 a Scheme of energy diagram in a typical PEC system. Ein: built-in electric field in depletion region, Ef: Fermi level, Ec: conduction band, Ev: valence band, Efn: quasi-Fermi level of holes, Efp: quasi-Fermi level of electrons. PEC systems with different models of $\mathbf{b}$ photoanode and photocathode, $\mathbf{c}$ photoanode alone, and $\mathbf{d}$ photoanode along with PSII and A+/A*redox couple. Reproduced with permission from Ref. [47]. Copyright 2015 Wiley-VCH

with relatively slow reaction kinetics. As a result, an overpotential is required to achieve the efficient water splitting reaction [57]. In general, the higher reaction overpotential implies the lower solar energy conversion efficiency. A feasible approach is to introduce active electrocatalysts as cocatalysts into the semiconductor photoelectrode to enhance reaction kinetics and decrease overpotentials for the HER and OER reactions in a PEC system [58]. Notably, many semiconductor-based photoelectrodes suffer from chemical corrosion in solution, thereby leading to unstable operation in applications [59]. Therefore, certain efforts have been made to introduce a protective interlayer to isolate the photoresponsive semiconductor from the electrolyte and promote long-term stability of the integrated photoelectrodes. Consequently, the overall solar conversion efficiency of a PEC system is determined by the photochemical and electrocatalytic processes that take place at the semiconductor interlayer and photoelectrode-electrolyte interfaces, respectively [60].

In a photoelectrode, a semiconductor layer mainly acts as a light absorber to produce photogenerated electrons and holes; subsequently, these generated electrons and holes are separated and transferred to the electrode interface for surface redox reactions. It was reported that the potentials and concentrations of the photogenerated charge carriers are closely related to the PEC redox reactions. A common problem is that only a small number of photogenerated charge carriers near the depletion layer of the semiconductor can be separated and transferred to the electrode interface for driving the water splitting reactions. Therefore, it can be concluded that solar-driven water splitting efficiency of a photoelectrode in a PEC system is determined by the three main factors, including (i) photon absorption capability, (ii) 
photogenerated charge separation and transfer efficiency, as well as (iii) multi-step surface catalytic reaction rate.

First, the absorption efficiency of the incident light has a strong correlation with the intrinsic extinction coefficient and semiconductor nanostructure, which largely determines the maximum range of the utilizable sunlight spectrum [61-63]. When the semiconductor photoelectrode possesses a suitable bandgap energy for harvesting solar energy, the adequate photoinduced potential can be produced for the surface catalytic reactions.

Second, the separation and transfer efficiency of photoinduced charge carriers mainly depends on the recombination and mobility of photogenerated electrons and holes inside semiconductors [64-66]. If the lifetime and diffusion distance of photoexcited charge carriers are longer and larger, respectively, it is easier to separate and transport the carriers, leading to the higher process efficiencies.

Third, the surface catalytic reaction rate is related to the charge injection efficiency and co-catalysts activity at the electrode-electrolyte interface. Moreover, during these photogenerated charge movement processes, the series resistances involved in the PEC systems will undermine both the photocurrent density and photoinduced potential. Consequently, the required overpotentials inevitably become higher and the solar energy conversion efficiency is reduced.

Essentially, the PEC efficiency of water splitting for a photoelectrode mainly depends on the above-mentioned light harvesting efficiency, charge separation and transfer efficiency, and surface catalytic reaction efficiency. A proper design of light absorbers, interfacial properties, and co-catalysts can effectively enhance the separation efficiency of photogenerated charge carriers and reduce the transportation resistances and overpotentials for catalytic reactions [67-69]. In addition, different synthetic methods and materials configurations, such as semiconductor types, crystal phases, and morphologies, also affect the mentioned efficiencies in a PEC device. Notably, a two-component photoelectrode consists of semiconductor support materials as light absorbers and active materials as co-catalysts. Meanwhile, three or more components can be properly integrated together to fabricate more elaborate and efficient photoelectrodes to further increase the efficiencies of sunlight harvesting, photoinduced charge separation and transportation, and surface catalytic reactions.

These points give a clear guidance for the initial screening of desirable photoelectrode materials and device optimizations at a later stage. Apart from these factors, more convincing and accurate parameters, for instance, onset potential, photocurrent density, incident photon-to-current efficiency (IPCE), and catalyst stability, are required to select the optimal photoelectrode materials.

Furthermore, in order to clearly understand the PEC mechanism and further obtain high water splitting performance, tremendous efforts have been made to experimentally measure the photoinduced charge carrier dynamics, including separation, transportation, and recombination. Various frequency- and time-resolved spectroscopy techniques have been developed, such as electrochemical impedance spectroscopy (EIS), transient photocurrent spectroscopy, and intensity-modulated photocurrent/photovoltage spectroscopy (IMPS/IMVS) [70-72]. Among them, EIS spectroscopy is widely utilized to explore photogenerated charge dynamics and recombination kinetics in the photoelectrodes, where the impedance of a system can be measured over a range of frequencies, thereby facilitating to reveal the frequency response (such as dissipation properties) of the PEC system [73]. Besides, transient absorption spectroscopy (TAS) is an effective tool to obtain absorption and concentration data of photoinduced charge carriers in the PEC system, which is helpful to measure the lifetime of photogenerated electrons and holes, and thereby analyze transport and recombination dynamics in photoelectrodes on the picosecond to microsecond time scales [74-76]. Moreover, time-resolved photoluminescence (TRPL) spectroscopy is also a powerful technique for charge carrier dynamic measurements, which can provide valuable information on photogenerated charge carrier lifetime and electron-hole diffusion length for investigating the size-, surface- and interface-dependent effects [77].

\section{2D Photoelectrodes Integrated with Nanocarbons Co-catalysts}

\subsection{Graphitic Carbon Nitride (GCN)}

Metal-free layered GCN has attracted attention as a 2D photocatalyst material owing to its facile synthesis, low cost, and long-term stability. For a PEC system, a suitable bandgap of $\sim 2.7 \mathrm{eV}$ with the appropriate band positions makes GCN a promising candidate for water splitting [78-80]. However, the solar-to-energy conversion efficiency of GCN photocatalysts is still far from satisfactory due to the limited light harvesting ability, excessive recombination of photogenerated 
electron-hole pairs, poor charge carrier transport efficiency, and slow interfacial reaction kinetics in PEC water splitting.

To overcome these weaknesses of the GCN photoelectrodes, introducing nanocarbons as co-catalysts has been widely explored in the past decades. As a 0D carbon material, carbon dots (CDs) with the primary particles sizes of $2-10 \mathrm{~nm}$ could be anchored on the surface of GCN via $\pi-\pi$ stacking interactions, thus leading to the narrowed bandgap and enhanced light response [81, 82]. Owing to the formation of van der Waals heterojunction between the CDs and $\mathrm{GCN}$, as well as high conductivity of CDs, the separation efficiency of photogenerated charge carries on the CDs/GCN interface could be enhanced [83]. For example, Kang et al. reported that coupling of CDs with porous GCN together via the negative surface charge interaction boosted the quantum efficiencies to the maximum value of $16 \%$ at $420 \mathrm{~nm}$ with the overall solar energy conversion efficiency of $2.0 \%$ under AM 1.5G solar illumination [84]. Besides, Guo et al. fabricated a $p$-CN/CDs hybrid as an integrated photoanode using an electrostatic attraction technique. The photoanode showed an enhanced anodic photocurrent density of $38 \mu \mathrm{A} \mathrm{cm} \mathrm{cm}^{-2}$ at $1.0 \mathrm{~V}$ vs. RHE with IPCE of $7.0 \%$ at $420 \mathrm{~nm}$ under AM $1.5 \mathrm{G}$ illumination, which were three and two times higher than the pristine $p$-CN, respectively [85]. The calculated conduction band potential of $-0.59 \mathrm{eV}$ for $p$-CN/CDs demonstrated the desirable thermodynamic merit for PEC-HER.

Compared with the OD CDs providing only the point-topoint contact in a heterojunction, coupling GCN nanosheets with other carbon materials, such as 2D graphene, can further increase the contact area for fast charge transfer and further improve the PEC conversion efficiency. Recently, a layered $\mathrm{CN} /$ reduced graphene oxide (CN-RGO) photoelectrode with rich porous structure was synthesized [86]. In the CN-RGO, the layered heterojunction provided the longer electron diffusion distance of up to $36 \mu \mathrm{m}$, higher active surface area, and larger light-response range in comparison with pristine $\mathrm{CN}$. Based on these advantages, the IPCE of the optimized CN-RGO photoanode was impressive $5.3 \%$ at $400 \mathrm{~nm}$ with a redshift onset wavelength at around $510 \mathrm{~nm}$. Further, the photocurrent density of CN-RGO reached $75 \mu \mathrm{A} \mathrm{cm}^{-2}$ at $1.23 \mathrm{~V}$ vs. RHE without any hole scavenging layer, which was 20 times larger than in the pristine $\mathrm{CN}$. Meanwhile, the external quantum efficiency reached $5.5 \%$ at $400 \mathrm{~nm}$. Acting as an effective charge transfer bridge, the RGO with excellent conductivity could efficiently accelerate the photoinduced electron transfer from GCN to the substrate, thereby increasing the PEC-HER efficiency. Besides, Leung et al. reported an RGO-modified g- $\mathrm{C}_{3} \mathrm{~N}_{4} / \mathrm{Ni}$ foam photoanode, in which a heterostructure between $\mathrm{g}_{-} \mathrm{C}_{3} \mathrm{~N}_{4}$ and RGO was formed, thus improving PEC-HER performance [87]. The optimized photoanode of $\mathrm{g}_{-} \mathrm{C}_{3} \mathrm{~N}_{4} / \mathrm{RGO}$ (CNG)-Ni foam showed a stable transient photocurrent density of $0.5 \mathrm{~mA} \cdot \mathrm{cm}^{-2}$ at $0.4 \mathrm{~V}$ vs. SCE with the maximum $\mathrm{H}_{2}$ production rate of $6.0 \mathrm{mmol} \mathrm{h}^{-1}$ $\mathrm{cm}^{-2}$, which were 2.5 and 2.0 times higher than the pristine g- $\mathrm{C}_{3} \mathrm{~N}_{4}$, respectively. Under visible light illumination, the photoinduced electrons produced at $\mathrm{g}-\mathrm{C}_{3} \mathrm{~N}_{4}$ can be rapidly transferred to RGO and $\mathrm{Ni}$ foam for $\mathrm{H}_{2}$ evolution due to the strong interaction between $\mathrm{g}-\mathrm{C}_{3} \mathrm{~N}_{4}$ and RGO.

Apart from conventional 2D GCN/RGO systems, GCN/ RGO hybridized heterostructure was also designed and fabricated for efficient PEC water splitting. Recently, a ternary 2D g- $\mathrm{C}_{3} \mathrm{~N}_{4} / \mathrm{N}$-doped graphene/2D $\mathrm{MoS}_{2}\left(\mathrm{CNNS} / \mathrm{NRGO} / \mathrm{MoS}_{2}\right)$ photoanode was developed via a facile sol-gel deposition route (Fig. 3a, b) [88]. Firstly, the CNNS/NRGO composite was prepared via one-step pyrolysis of urea and GO, where $\mathrm{N}$-containing species were released from polycondensation of urea, resulting in partial reduction and N-doping of GO. Subsequently, the $\mathrm{MoS}_{2}$ nanosheets were introduced into CNNS/NRGO hybrid via a hydrothermal treatment to form the CNNS/NRGO/MoS ${ }_{2}$ hybrid. In this unique 2D/2D/2D architecture, the NRGO worked as a charge transfer channel for accelerating electron transfer between $\mathrm{g}-\mathrm{C}_{3} \mathrm{~N}_{4}$ and $\mathrm{MoS}_{2}$, and the $\mathrm{g}_{-} \mathrm{C}_{3} \mathrm{~N}_{4}$ was used to efficiently harvest sunlight due to its suitable bandgap. Meanwhile, layered $\mathrm{MoS}_{2}$ enhanced the light absorption ability, promoted charge carrier separation and transfer across the $\mathrm{NRGO} / \mathrm{MoS}_{2}$ interface, as well as provided more exposed active sites for PEC-HER. Therefore, such a PEC system was endowed with broadened light harvesting range, shortened charge diffusion distance, and enlarged contact area for the efficient PEC water splitting. As a result, the $\mathrm{CNNS} / \mathrm{NRGO} / \mathrm{MoS}_{2}$ heterojunction exhibited the substantially improved photocurrent density of $37.6 \mu \mathrm{A} \mathrm{cm}^{-2}$ upon loading NRGO, namely 1.46 and 3.43 times higher than that of the two-component CNNS/MoS $2\left(25.7 \mu \mathrm{A} \mathrm{cm}^{-2}\right)$ and CNNS (11 $\mu \mathrm{A} \mathrm{cm}^{-2}$ ) at $0.9 \mathrm{~V}$, respectively, as shown in Fig. 3c.

Furthermore, as a unique 2D single-atom-thick carbon allotrope, GDY has attracted great interest in the fields of photo/electro catalysis, solar cells, and batteries. Benefitting from the unique $s p$ and $s p^{2}$ mixture carbon atoms, moderate bandgaps of $0.44-1.47 \mathrm{eV}$, and high charge carrier mobility of $10^{4}-10^{5} \mathrm{~cm}^{2} \mathrm{~V}^{-1} \mathrm{~s}^{-1}$ [89], the GDY can serve as an efficient modifier to enhance the PEC water splitting 

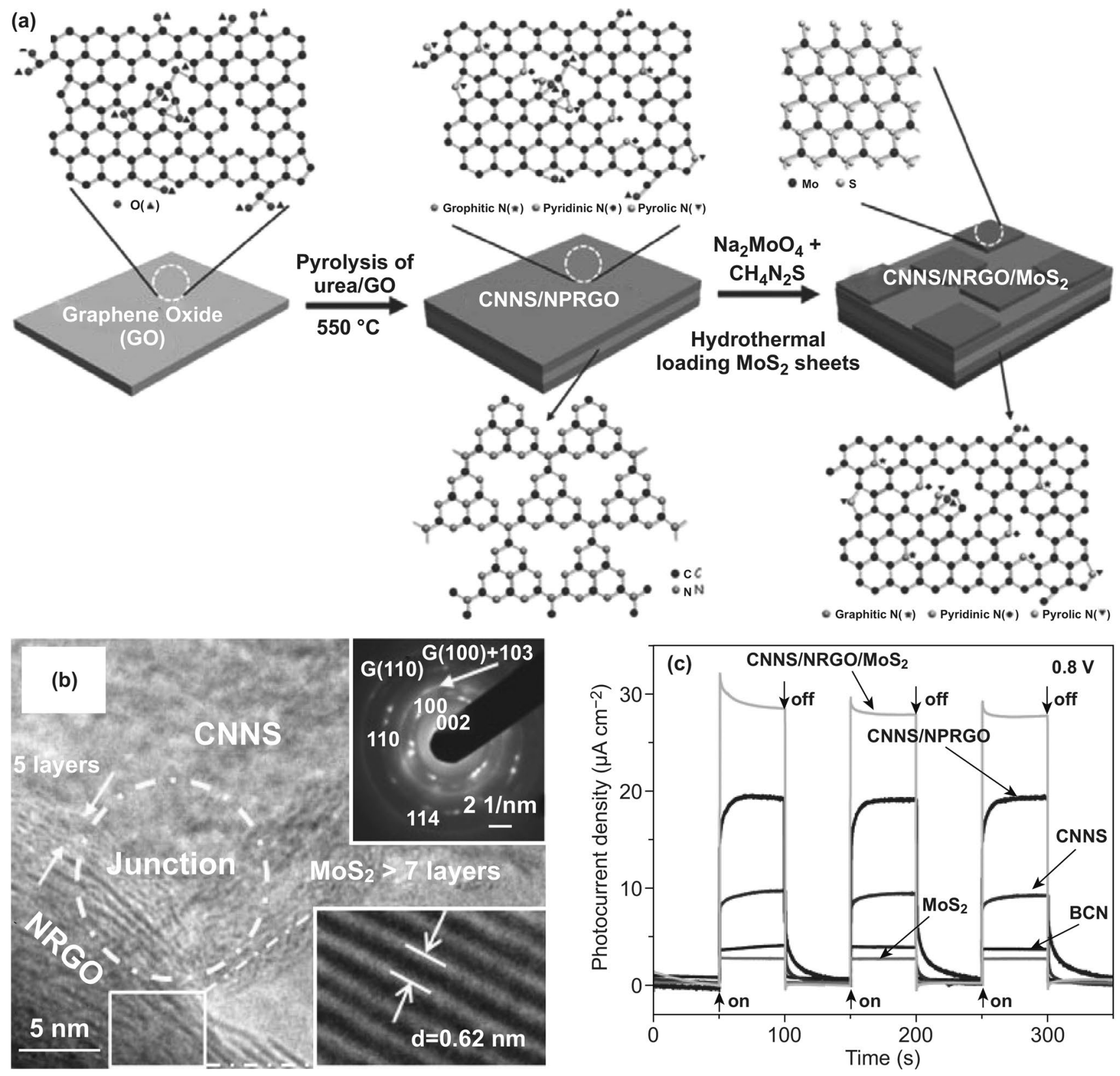

Fig. 3 a Synthetic scheme of CNNS/NRGO/MoS 2 . b HRTEM image of CNNS/NRGO/MoS 2 c Transient photocurrent density vs. time plotted for BCN, $\mathrm{MoS}_{2}$, CNNS, CNNS/NPRGO, CNNS/NRGO/MoS 2 . Reproduced with permission from Ref. [88]. Copyright $2013 \mathrm{Wiley-VCH}$

performance, such as the previously reported GDY/BiVO [90] and CdSe QDs/GDY [91]. As a typical example, Lu et al. [92] constructed a $\mathrm{g}-\mathrm{C}_{3} \mathrm{~N}_{4} / \mathrm{GDY}$ heterojunction as an excellent photocathode for PEC-HER, as shown in Fig. 4a. The stable $2 \mathrm{D} / 2 \mathrm{D} \mathrm{g}-\mathrm{C}_{3} \mathrm{~N}_{4} / \mathrm{GDY}$ heterojunction with ultrathin layered structure (Fig. 4b), high charge carrier mobility, and large surface area were beneficial for the efficient transfer of photoinduced holes and electrons, suppressed recombination of photogenerated charge carries, while exposing more active sites. In Fig. 4c, the formed 2D/2D heterojunction in g- $\mathrm{C}_{3} \mathrm{~N}_{4} / \mathrm{GDY}$ hybrid was clearly observed, which could offer large face-to-face interface between $\mathrm{g}_{-} \mathrm{C}_{3} \mathrm{~N}_{4}$ and GDY, and short distance channels for transportation of photoinduced charge carriers. The layered $\mathrm{g}-\mathrm{C}_{3} \mathrm{~N}_{4}$ interfaced with the 2D GDY was further verified by EDX elemental mapping in Fig. 4d-g. Owing to the suitable band alignments of $\mathrm{g}-\mathrm{C}_{3} \mathrm{~N}_{4}$ 
and GDY (Fig. 4h), the photoinduced holes extracted from g- $\mathrm{C}_{3} \mathrm{~N}_{4}$ could effectively transfer to the GDY. Therefore, the photogenerated electrons and holes were sufficiently separated under the external electric field. Meanwhile, the g- $\mathrm{C}_{3} \mathrm{~N}_{4} /$ GDY hybrid exhibited the sevenfold increase in the electron lifetime $(610 \mu \mathrm{s})$ and the threefold increase in the photocurrent density $\left(-98 \mu \mathrm{A} \mathrm{cm}^{-2}\right.$ at $0 \mathrm{~V}$ vs. NHE) in comparison with the pristine $\mathrm{g}_{-} \mathrm{C}_{3} \mathrm{~N}_{4}\left(88 \mu \mathrm{s}\right.$ and $\left.-32 \mu \mathrm{A} \mathrm{cm}{ }^{-2}\right)$ in $0.1 \mathrm{M} \mathrm{Na}_{2} \mathrm{SO}_{4}$ solution, as presented in Fig. $4 \mathrm{i}$, which indicates that the $\mathrm{g}_{-} \mathrm{C}_{3} \mathrm{~N}_{4} / \mathrm{GDY}$ photoanode displayed an excellent performance for PEC-HER.

\subsection{Transition Metal Dichalcogenides (TMDs)}

In comparison with the GCN, layered TMD materials can offer richer active sites and thickness-dependent electronic structures, which is beneficial for the solar energy conversion to produce hydrogen fuel. Generally, TMD materials, including more than 40 kinds of stable 2D materials, can be denoted as $\mathrm{MX}_{2}$ (M means transition metal element, and $\mathrm{X}$ represents $\mathrm{S}, \mathrm{Se}$, and $\mathrm{Te}$ ), which possess similar structural properties [93]. Their bulk form is mainly made of X-M-X layers, while the neighboring layers are connected by van der Waals interactions. Nevertheless, the electronic properties of TMD materials are closely related with the atomic compositions. For instance, $\mathrm{MoS}_{2}$ and $\mathrm{MoSe}_{2}$ are semiconductors, while $\mathrm{WTe}_{2}$ and $\mathrm{VS}_{2}$ are semimetals, and $\mathrm{TaS}_{2}$ and $\mathrm{NbS}_{2}$ are metals.

Recently, it was found that the atomic layer number of TMDs materials strongly affects their optoelectronic properties. Based on the theoretical and experimental studies, it was reported that monolayer $\mathrm{MoS}_{2}$ has a direct bandgap of $1.9 \mathrm{eV}$, while the corresponding bulk $\mathrm{MoS}_{2}$ has an indirect bandgap of $1.3 \mathrm{eV}$ [94]. Furthermore, it was demonstrated that with the decreasing of atomic layer number, the semiconducting $2 \mathrm{H}-\mathrm{MoS}_{2}$ transforms to metallic $1 \mathrm{~T}-\mathrm{MoS}_{2}$. This feature is beneficial for accelerating the movement of photogenerated charge carriers, thereby injecting more charge carriers into the electrocatalyst-electrolyte interface for catalytic reaction. Recently, Chen et al. reported that the nanostructured $\mathrm{MoS}_{2}$ possessed the higher photocurrent density in comparison with bulk $\mathrm{MoS}_{2}$ for PEC-HER [95].

The surface defects in nanostructured $\mathrm{MoS}_{2}$ also play the key role in determining overall water splitting activity of photoelectrodes. By means of in situ corrosion of bulk
$\mathrm{MoS}_{2}$, the creation of surface defects led to the decrease in photocatalytic activity, while these produced edge sites in turn enhanced electrocatalytic HER performance. Compared to $\mathrm{S}$ atoms with the two-atom coordination, the mono-coordinated $\mathrm{S}$ atoms exhibited the higher catalytic activity. However, the $\mathrm{S}$ atoms with three-atom coordination located at the basal plane were saturated atoms with no photoactivity. For unsaturated active $\mathrm{S}$ atoms, they could strongly bond to $\mathrm{H}^{+}$in a lactic acid solution and easily reduce $\mathrm{H}^{+}$to $\mathrm{H}_{2}$ in the presence of photogenerated electrons [96]. It was concluded that the highly active nanosized $\mathrm{MoS}_{2}$ with more exposed edges can provide high HER activity in a photochemical/PEC system. Therefore, based on these merits, 2D nanostructured TMDs catalysts were widely fabricated in the past decades as active components to fabricate the integrated photoelectrodes for PEC water splitting [97-101].

However, due to the ultrafast transport of photogenerated charge carriers, the produced electrons and holes are easily recombined, thus decreasing the PEC performance of 2D TMDs photoelectrodes for water splitting [102, 103]. Therefore, to further improve the PEC activity of 2D TMDs-based photoelectrodes, several nanocarbon co-catalysts have been introduced to boost the separation and transfer of photogenerated charge carriers [104]. For instance, Agnoli and coworkers fabricated a $p-n \mathrm{MoS}_{2} / \mathrm{N}$-doped cGO heterojunction through an aerosol process in a furnace at $900{ }^{\circ} \mathrm{C}$ for enhancing PEC-HER, as shown in Fig. 5a [105]. The N-doped cGO/MoS ${ }_{2}$ hybrid enhanced the HER activity evidenced by the lower overpotential of $\sim 100 \mathrm{mV}$ vs. RHE, higher photocurrent density, and smaller Tafel slope with respect to commercial $\mathrm{MoS}_{2}$ (Fig. 5b, c). The enhanced PEC-HER activity over the $\mathrm{N}$-doped $\mathrm{cGO} / \mathrm{MoS}_{2}$ hybrid was mainly caused by the formation of a localized $p-n$ heterojunction, which facilitated the efficient separation of photogenerated charge carriers.

Subsequently, more attention has been drawn to threecomponent 2D photocathodes, such as $\mathrm{RGO} / \mathrm{CdS} / \mathrm{MoS}_{2}$ hybrid, for PEC-HER, where the effects of charge transfer behavior and $\mathrm{MoS}_{2}$ crystal phase in 2D photocathode on the solar-driven HER were discussed [106]. Owing to the introduction of RGO, the chemical interaction took place between $\mathrm{S}$ atoms in $\mathrm{CdS} / \mathrm{MoS}_{2}$ and $\mathrm{C}$ atoms in RGO. The strong electronic interaction between $\mathrm{MoS}_{2}$ and RGO was enabled due to the intimate contact, which was beneficial for photoinduced charge separation and transfer with the higher 

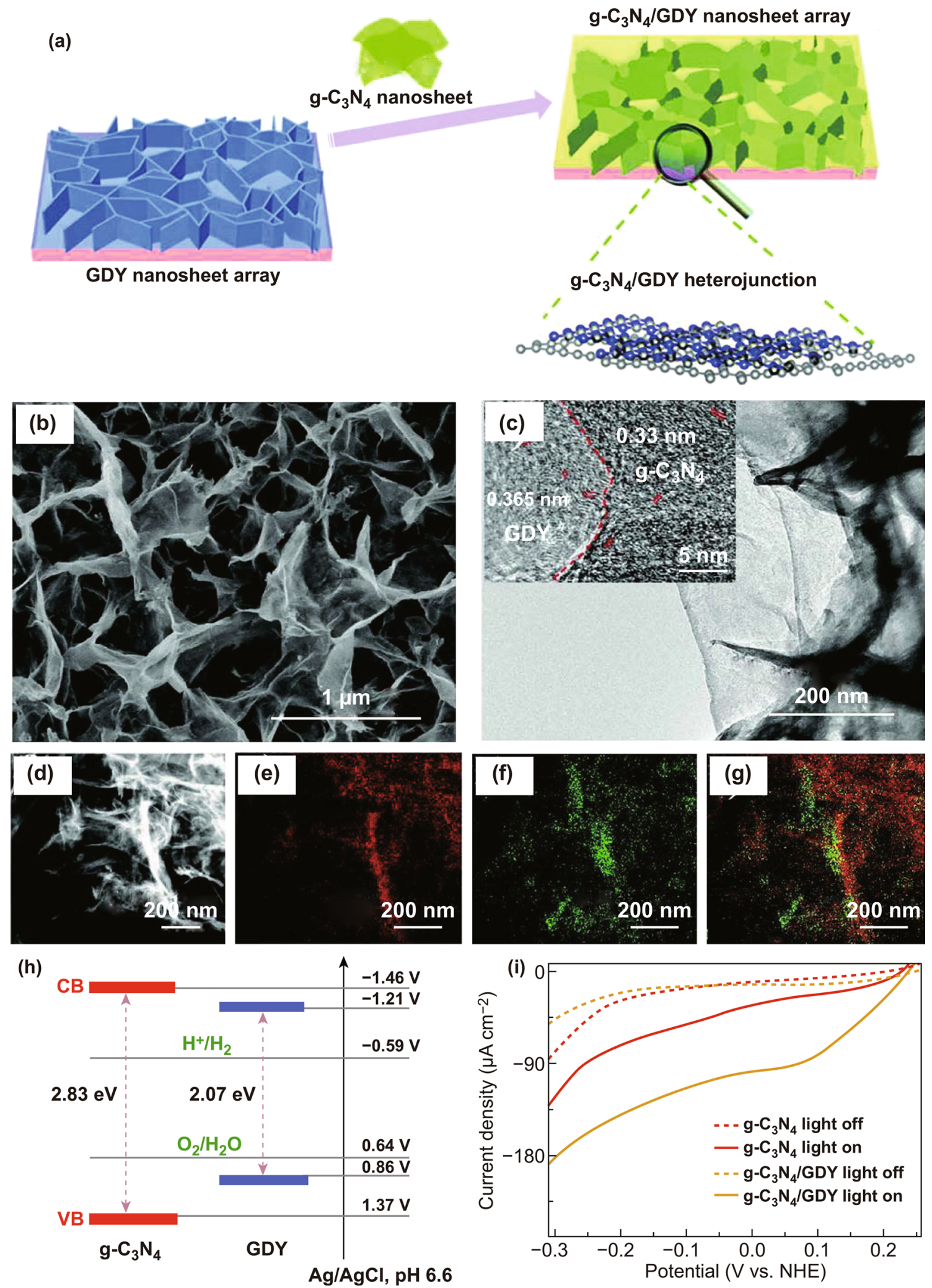

Fig. 4 a Synthesis scheme of $2 \mathrm{D} / 2 \mathrm{D}$ g- $\mathrm{C}_{3} \mathrm{~N}_{4} / \mathrm{GDY}$; b SEM and c TEM images of $\mathrm{g}-\mathrm{C}_{3} \mathrm{~N}_{4} / \mathrm{GDY}$; $\boldsymbol{d}$ high-angle annular dark field (HAADF) image, e C, $\mathbf{f ~ N}$, and $\mathbf{g}$ mixed elemental mapping of $\mathbf{g}-\mathrm{C}_{3} \mathrm{~N}_{4} / \mathrm{GDY}$; $\mathbf{h}$ band alignments of $\mathrm{g}-\mathrm{C}_{3} \mathrm{~N}_{4}$ and GDY; i linear sweep voltammetry of $\mathrm{g}_{-} \mathrm{C}_{3} \mathrm{~N}_{4} / \mathrm{GDY}$ under light on and off. Reproduced with permission from Ref. [92]. Copyright 2018 WILEY 
charge density and lower resistance at solid-solid interface, thus boosting the PEC-HER activity.

Besides, nanosized CDs ( $<10 \mathrm{~nm}$ ) have been utilized to modify the TMDs-catalyzed photoelectrodes due to their intrinsically pronounced $\pi$-conjugated system, which is beneficial for the rapid electron transfer between TMDs and CDs [107-109]. For example, Kang and co-workers synthesized a CDs decorated $\mathrm{MoS}_{2}$ nanosheets via a facile hydrothermal route [110].

The CD-modified $\mathrm{MoS}_{2}$ exhibited the significantly enhanced HER ability under visible light irradiation. The mechanism of the improved HER activity of $\mathrm{CDs} / \mathrm{MoS}_{2}$ can be attributed to the decreased number of $\mathrm{S}^{4+}$ and increased amount of $\mathrm{S}_{2}{ }^{2-}$ and $\mathrm{S}^{2-}$ sites, which accelerated the charge carriers transfer between $\mathrm{CDs}$ and $\mathrm{MoS}_{2}$. Apart from a small Tafel slope of $45 \mathrm{mV} \mathrm{dec}^{-1}$ with the reasonably good stability in $0.5 \mathrm{M} \mathrm{H}_{2} \mathrm{SO}_{4}$, the synthesized $\mathrm{CDs} / \mathrm{MoS}_{2}$ displayed a smaller overpotential of $\sim 125 \mathrm{mV}$ at $10 \mathrm{~mA} \mathrm{~cm}^{-2}$ than single $\mathrm{MoS}_{2}$. Meanwhile, it was found that the duration of visible light irradiation affected the HER activity, which can be attributed to the extent of reduction in $\mathrm{MoS}_{2}$ edges and the formation of surface defects.
Recently, layered GDY nanosheets have also been utilized to modify the TMD-based photoelectrodes to enhance HER performance. For example, He et al. reported an effective approach to fabricate GDY-coated $\mathrm{MoS}_{2}$ nanosheets on a carbon fiber (CF) network for boosting the HER activity under both acidic and alkaline conditions [111]. The theoretical calculations results inferred that the added GDY could effectively anchor on the surface of $\mathrm{MoS}_{2}$ nanosheets and result in the transformation of $\mathrm{MoS}_{2}$ nanosheets from $2 \mathrm{H}$ to $1 \mathrm{~T}$ phases, which strongly facilitated the transfer of photogenerated charge carriers from $\mathrm{MoS}_{2}$ to GDY, as shown in Fig. 6a, b. Upon the coupling of $\mathrm{MoS}_{2}$ nanosheets with layered GDY, a hierarchical porous network of GDY-MoS ${ }_{2} \mathrm{NS} / \mathrm{CF}$ was successfully synthesized, as displayed in Fig. 6c-e, in which the GDY was tightly bonded with $\mathrm{MoS}_{2}$ nanosheets with rich porosity, beneficial for improving catalytic activities. Meanwhile, the alkaline PEC tests revealed that the GDY-MoS NS/CF hybrid had excellent HER activity with a low overpotential of $90 \mathrm{mV}$ at $10 \mathrm{~mA} \mathrm{~cm}{ }^{-2}$ current density. Such performance was significantly superior to that of $20 \% \mathrm{Pt} / \mathrm{C}$, $\mathrm{MoS}_{2} \mathrm{NS} / \mathrm{CF}$, and GDY/CF catalysts, as presented in Fig. $6 \mathrm{f}$. Moreover, the hybridized GDY-MoS ${ }_{2}$ NS/CF exhibited the
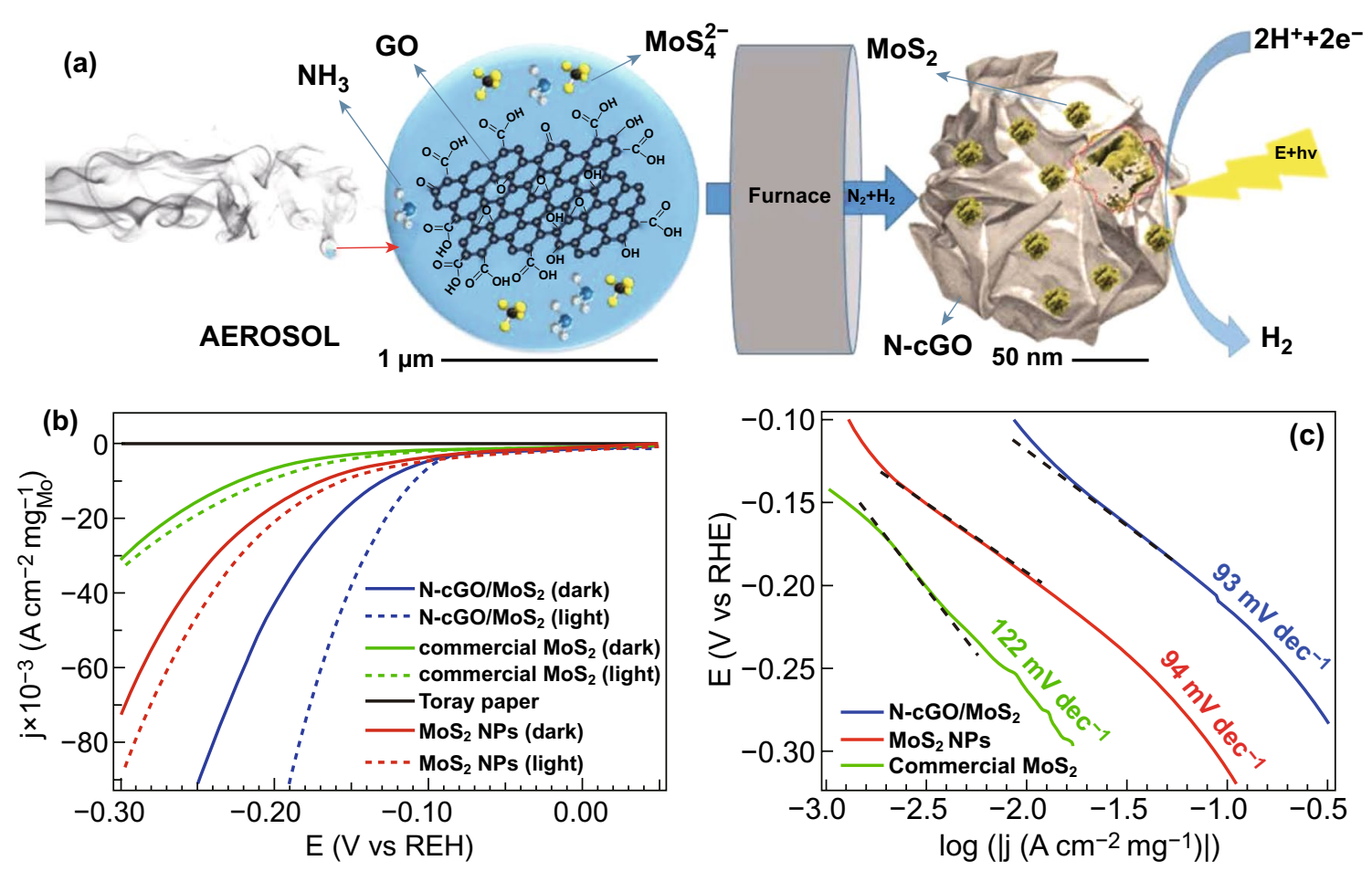

Fig. 5 a Synthesis scheme of $\mathrm{N}-\mathrm{cGO}_{\mathrm{MoS}}$; b polarization curves in dark and under illumination and c Tafel plots for N-cGO/MoS ${ }_{2}$, MoS 2 $\mathrm{NPs}$, and commercial $\mathrm{MoS}_{2}$ in $0.5 \mathrm{M} \mathrm{H}_{2} \mathrm{SO}_{4}$. Reproduced with permission from Ref. [105]. Copyright 2015 American Chemical Society 
apparently smaller Tafel slope of $87.5 \mathrm{mV} \mathrm{dec}^{-1}$ than the $\mathrm{MoS}_{2}$ NS/CF and GDY/CF (Fig. 6g). Under the visible light irradiation, the photocurrent density of GDY- $\mathrm{MoS}_{2} \mathrm{NS} / \mathrm{CF}$ hybrid reached to $102 \mu \mathrm{A} \mathrm{cm}^{-2}$, which was approximately 46 times higher than that of pristine $\mathrm{MoS}_{2} \mathrm{NS} / \mathrm{CF}$, further verifying the expected recombination suppression of the photogenerated charge carriers. In such GDY-MoS 2 NS/ CF structure, the electron-rich GDY not only provides more active sites to anchor active materials in the electrolyte, but also facilitates the photogenerated charge transport, thanks to excellent charge carrier mobility and electric conductivity of GDY, thereby improving HER activity.

\subsection{MXenes}

Among various 2D materials, metal-free GCN and TMDs materials show high potential for fabricating high-quality photoelectrodes, while new layered MXene structures have
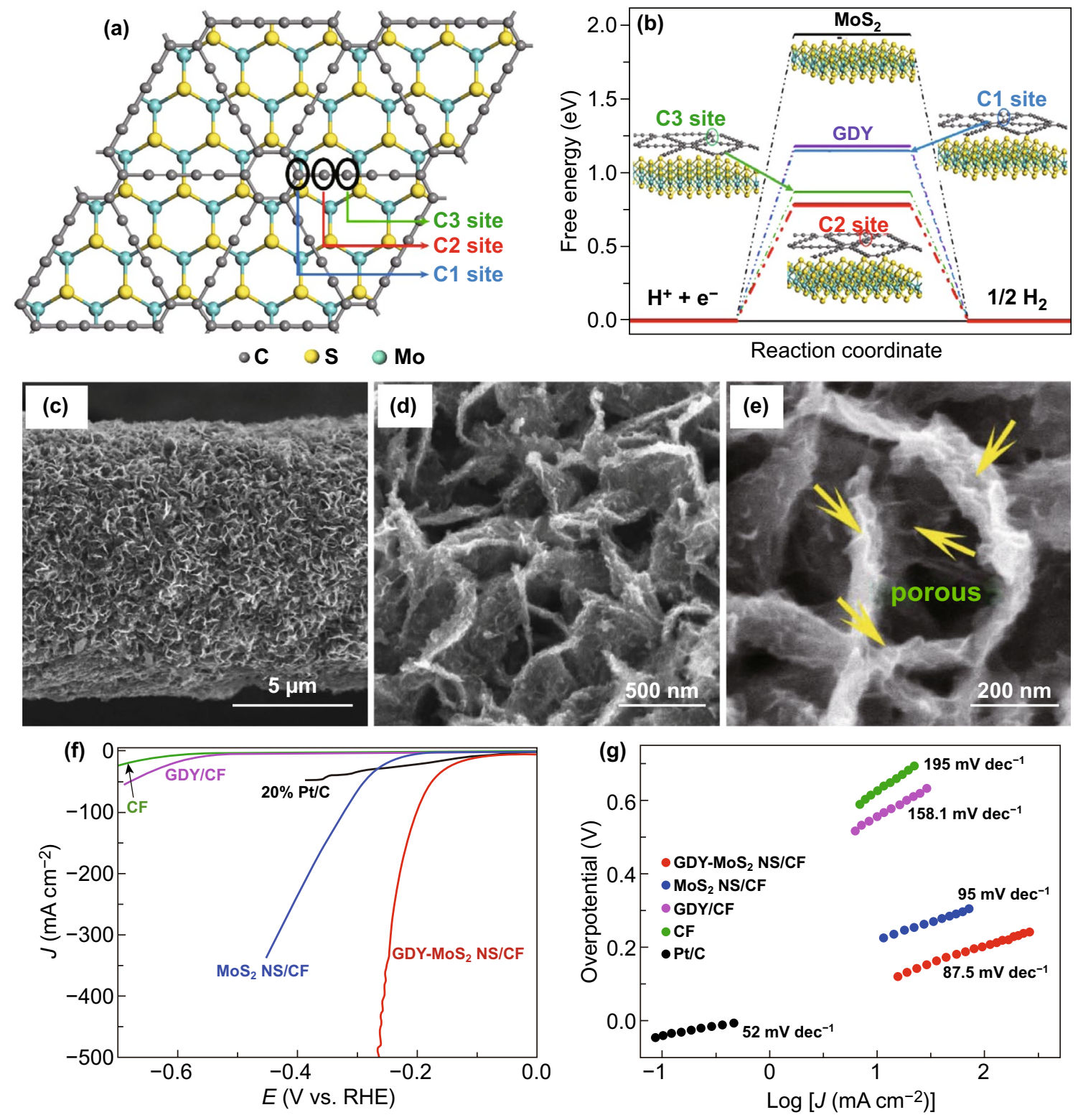

Fig. 6 a Top view of the optimized GDY-MoS ${ }_{2}$, b calculated free energy of HER at equilibrium potential for MoS ${ }_{2}$, GDY and different sites in GDY-MoS 2 hybrid, c-e SEM images of GDY-MoS 2 NS/CF, $\mathbf{f}$ linear sweep voltammetry curves, and $\mathbf{g}$ corresponding Tafel plots of GDY-MoS 2 $\mathrm{NS} / \mathrm{CF}, \mathrm{MoS}_{2} \mathrm{NS} / \mathrm{CF}, \mathrm{GDY} / \mathrm{CF}, \mathrm{CF}$, and Pt/C. Reproduced with permission from Ref. [111]. Copyright 2019 Elsevier 
recently attracted strong interest for the assembly of PEC system for water splitting. MXenes, a new and promising class of over 60 kinds of 2D metal carbides, nitrides or carbonitrides, is utilized to construct various electrodes applied in supercapacitors, photoelectrocatalysis, and photovoltaics [112-114]. In the past decade, MXenes have demonstrated many unique advantages to improve the PEC efficiency. For example, numerous unsaturated metal sites (such as $\mathrm{Ti}, \mathrm{Nb}$ or $\mathrm{V}$ ) are exposed due to the formation of 2D layer structures, which can result in the high redox reactivity compared to the single elemental carbon materials. Meanwhile, hydrophilic functionalities (such as - $\mathrm{OH}$ and $-\mathrm{O}$ ) are dangled on the surface of MXenes, which is beneficial to bond with the diverse device components, such as semiconductors, as well as to stabilize 2D MXenes in aqueous solution over a long term. On the other hand, similar to graphene, MXene has excellent metallic conductivity, which also helps ensure the efficient charge transfer. With the above outstanding properties of the MXene family, 2D MXenes represent promising materials to construct the efficient photoelectrodes [115]. Similar to graphene, from the top view, monolayer MXene possesses a hexagonal lattice with a rhombohedral unit cell. From the side view, tri-layer sheets contribute to monolayer MXene, including two M transition metal layers sandwiching one $\mathrm{X}$ layer, which can function as active catalytic sites for HER. Nevertheless, MXene materials working as HER electrode require a high overpotential for water splitting [116]. Therefore, integrating MXene photoelectrode with new functional components is a feasible approach to overcome this weakness.

Recently, nanocarbons have been encapsulated into MXene-based systems for promoting strong interfacial coupling and improving the separation and injection efficiency of photogenerated charge carriers [117, 118]. For instance, Qiu's group took advantage of the carbon encapsulation route to not only stabilize the $2 \mathrm{D} \mathrm{Ti}_{3} \mathrm{C}_{2}$-MXene material, but also to construct a hierarchical $\mathrm{MoS}_{2} / \mathrm{Ti}_{3} \mathrm{C}_{2}$-MXene@C heterojunction, which exhibited excellent HER performance and structural stability [119]. A small overpotential of $135 \mathrm{mV}$ at $10 \mathrm{~mA} \mathrm{~cm}{ }^{-2}$ was achieved using $\mathrm{MoS}_{2} /$ $\mathrm{Ti}_{3} \mathrm{C}_{2}$-MXene@C catalyst in a $0.5 \mathrm{M} \mathrm{H}_{2} \mathrm{SO}_{4}$ solution, as shown in Fig. 7a, b, while the onset potential was around $-20 \mathrm{mV}$ toward HER, which is close to commercial Pt/C. Meanwhile, Fig. 7c reveals that the Tafel slope of $\mathrm{MoS}_{2} /$ $\mathrm{Ti}_{3} \mathrm{C}_{2}$-MXene@ $\mathrm{C}$ significantly decreased to $45 \mathrm{mV} \mathrm{\textrm {dec } ^ { - 1 }}$ in comparison with the $\mathrm{Ti}_{3} \mathrm{C}_{2}$-MXene alone, while it was still inferior to conventional $\mathrm{Pt} / \mathrm{C}$ catalyst with $28 \mathrm{mV} \mathrm{dec}^{-1}$. As shown in Fig. 7d, the $\mathrm{MoS}_{2} / \mathrm{Ti}_{3} \mathrm{C}_{2}$-MXene@C exhibited a stable current density at a constant potential of $-130 \mathrm{mV}$ for a long period of $20 \mathrm{~h}$. Besides, Zhang et al. fabricated a cobalt-topped CNT/Ti ${ }_{3} \mathrm{C}_{2}$ nanosheet by ZIF-67 transformation [120]. The ZIF-67 as carbon source was transformed to the Co-CNTs on the $\mathrm{Ti}_{3} \mathrm{C}_{2}$ nanosheets via a pyrolysis process, where the layered $\mathrm{Ti}_{3} \mathrm{C}_{2}$ worked as conductive scaffolds to support the growth of Co-CNTs. Consequently, the Co$\mathrm{CNT} / \mathrm{Ti}_{3} \mathrm{C}_{2}$ exhibited a competitive electrocatalytic activity with the enhanced stability with respect to commercial $\mathrm{Pt} / \mathrm{C}$. One can attribute these achievements to the rich $\mathrm{Co}-\mathrm{N} / \mathrm{C}$ active sites, high graphitization, and large surface area.

These results indicated that 2D MXene/nanocarbons are indeed among the promising candidates as photocathodes in PEC system for the efficient renewable energy conversion. However, further improvements in PEC-HER activities over 2D MXene/nanocarbons photocathodes are required because 2D MXenes still do not present the expected photoresponse to produce photoinduced electrons and holes, which is important for solar-driven PEC-HER. Therefore, photoactive components should be introduced to form triadic photocathodes by coupling with 2D MXene/nanocarbons as co-catalysts due to their superior metal conductivity. The representative GCN-, TMDs- and LBO-based 2D photocathodes with nanocarbons for PEC-HER are summarized in Table 1.

\subsection{Layered Double Hydroxides (LDHs)}

The above-discussed GCN and TMDs materials are mainly utilized to assemble 2D photocathodes for PEC-HER. Correspondingly, the efficient $2 \mathrm{D}$ photoanodes for the PECOER are fabricated by using LDHs [121-123] and metal oxides [124-126]. Particularly, as a typical 2D material, LDHs have a layered stacking structure, where six oxygen atoms are situated at six corners and one transition metal atom is located at the center of an octahedron, denoted as $\mathrm{MO}_{6}$. These octahedrons further form a $2 \mathrm{D}$ layered structure by sharing the edge atoms. In general, the LDHs materials can be described by using a common chemical formula of $\mathrm{M}_{1}^{\mathrm{II}} \mathrm{M}_{x}^{\mathrm{III}}(\mathrm{OH})_{2}^{\mathrm{x}+}\left(\mathrm{A}^{\mathrm{n}-}\right)_{x / \mathrm{n}} \cdot \mathrm{mH}_{2} \mathrm{O}$ with brucite-like $\mathrm{M}^{\mathrm{II}}(\mathrm{OH})_{2}$ layers. Some of the $\mathrm{M}^{\mathrm{II}}$ cations can be replaced by $\mathrm{M}^{\mathrm{III}}$ cations, leading to the formation of positively charged layers; 

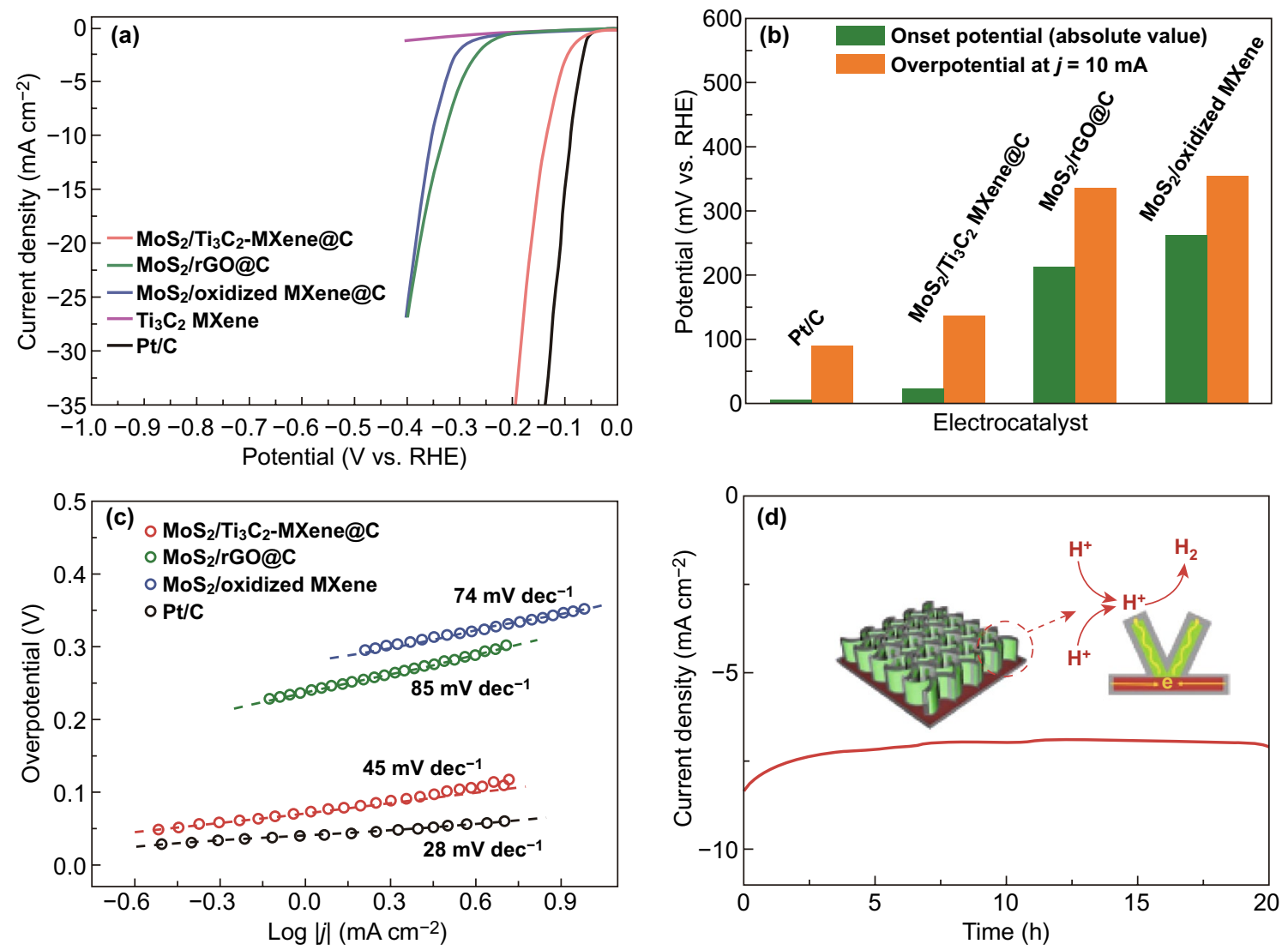

Fig. 7 a Polarization curves of $\mathrm{MoS}_{2} / \mathrm{Ti}_{3} \mathrm{C}_{2}-\mathrm{MXene} @ \mathrm{C}, \mathrm{MoS}_{2} / \mathrm{rGO} @ \mathrm{C}, \mathrm{MoS}_{2} /$ oxidized MXene, $\mathrm{Ti}_{3} \mathrm{C}_{2} \mathrm{MXene}$, and $\mathrm{Pt} / \mathrm{C}$ in $0.5 \mathrm{M} \mathrm{H}_{2} \mathrm{SO} \mathrm{O}_{4}$, b

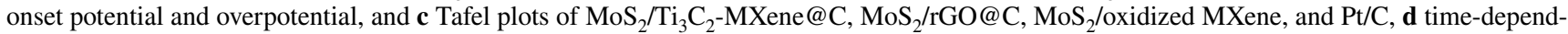
ent current density curves with overpotential of $130 \mathrm{mV}$ for $\mathrm{MoS}_{2} / \mathrm{Ti}_{3} \mathrm{C}_{2}-\mathrm{MXene} @ \mathrm{C}$. Reproduced with permission from Ref. [119]. Copyright 2017 WILEY-VCH

thus, more anions are subsequently required to maintain the charge balance. Monovalent cations (e.g., $\mathrm{Li}^{+}$), divalent cations (e.g., $\mathrm{Fe}^{2+}, \mathrm{Ni}^{2+}$ ) [127-129], or trivalent cations (e.g., $\left.\mathrm{Co}^{3+}, \mathrm{Ti}^{3+}\right)[130-132]$ are often formed by constructing the positively charged layers with partial cation substitution. Accordingly, other anions including $\mathrm{NO}_{3}{ }^{-}, \mathrm{SO}_{4}{ }^{2-}$, and $\mathrm{Br}^{-}$are often used to replace the original intercalation $\mathrm{CO}_{3}{ }^{2-}$ anion. The customized $2 \mathrm{D}$ nanosheets can form active sites exposed fully, thus optimizing the catalytic performance in various reactions [133-135]. The LDHs have attracted strong recent interest for OER catalysis under light irradiation [136-138]. It was reported that the 2D LDHs materials have numerous apparent advantages, for example, large surface area, abundant active sites, controllable layered structures, tunable chemical composition by varying the cations ratio, stable structure, and hierarchical porosity that is beneficial for water molecule diffusion and product release $[139,140]$. Furthermore, the strong electrostatic interactions between the anion and cation layers endow the LDHs materials with ordered arrangement of interlayer species and tailorable orientation of active sites, which accelerates the movement of photogenerated charge carriers, thus boosting the OER activity [141].

For pristine LDHs photoanodes, since the OER performance is still low in comparison with traditional metal oxide photoanodes, the introduction of a new constituent is necessary $[142,143]$. One of the feasible approaches is to combine with nanocarbon co-catalysts, such as 2D graphene and GDY, 1D CNTs or OD CDs. With the above-discussed merits, nanocarbons as co-catalysts can not only offer electrically conductive pathways to LDHs but also gainfully enlarge the surface area for fast mass transfer, which is expected to significantly increase charge carriers separation, transfer, and injection efficiencies [144-146]. 
Table 1 Comparison of PEC-HER activity of various 2D photocathodes

\begin{tabular}{|c|c|c|c|c|c|}
\hline Photocathodes & Synthesis method & Electrolyte & $J$ & IPCE & References \\
\hline $\mathrm{g}-\mathrm{C}_{3} \mathrm{~N}_{4} /$ carbon dots/PET & $\begin{array}{l}\text { Hydrothermal method and } \\
\text { electrophoretic deposi- } \\
\text { tion }\end{array}$ & $\begin{array}{l}5 \mathrm{v} / \mathrm{v} \% \text { triethanolamine } \\
\text { (TEOA) and } 0.5 \mathrm{M} \\
\mathrm{Na}_{2} \mathrm{SO}_{4}, \mathrm{pH}=10.5\end{array}$ & $\begin{array}{l}38 \mu \mathrm{A} \mathrm{cm} \mathrm{cm}^{-2} \text { at } 1 \mathrm{~V} \text { vs. } \\
\mathrm{RHE}\end{array}$ & $6.5 \%$ at $400 \mathrm{~nm}$ & {$[85]$} \\
\hline $\mathrm{CN}-\mathrm{RGO}$ & Calcination & $\begin{array}{l}10 \%(\mathrm{v} / \mathrm{v}) \text { TEOA and } \\
0.1 \mathrm{M} \mathrm{KOH}\end{array}$ & $\begin{array}{l}\sim 0.12 \mathrm{~mA} \mathrm{~cm}^{-2} \text { at } 1.23 \mathrm{~V} \\
\text { vs. RHE }\end{array}$ & $5.3 \%$ at $400 \mathrm{~nm}$ & {$[86]$} \\
\hline $\mathrm{g}-\mathrm{C}_{3} \mathrm{~N}_{4} / \mathrm{RGO} / \mathrm{Ni}$ foam & $\begin{array}{l}\text { Hydrothermal and electro- } \\
\text { phoretic deposition }\end{array}$ & $0.5 \mathrm{M} \mathrm{NaOH}, \mathrm{pH}=6.8$ & $\begin{array}{l}\sim 0.5 \mathrm{~mA} \mathrm{~cm}^{-2} \text { at } 0.4 \mathrm{vs} . \\
\mathrm{SCE}\end{array}$ & - & [87] \\
\hline $\mathrm{N}-\mathrm{cGO} / \mathrm{MoS}_{2}$ & Aerosol \& calcination & $0.5 \mathrm{M} \mathrm{H}_{2} \mathrm{SO}_{4}$ & $\begin{array}{l}\sim 0.14 \mathrm{~mA} \mathrm{~cm}^{-2} \text { at }-0.1 \mathrm{~V} \\
\text { vs. RHE }\end{array}$ & - & {$[105]$} \\
\hline $\mathrm{MoS}_{2} / \mathrm{CdS} / \mathrm{rGO}$ & Hydrothermal & $\begin{array}{l}0.35 \mathrm{M} \mathrm{Na}_{2} \mathrm{SO}_{3} \& 0.25 \mathrm{M} \\
\quad \mathrm{Na}_{2} \mathrm{~S}, \mathrm{pH}=12.5\end{array}$ & $\begin{array}{l}\sim 20.2 \mathrm{~mA} \mathrm{~cm}^{-2} \text { at }-0.6 \mathrm{~V} \\
\text { vs. RHE }\end{array}$ & - & {$[106]$} \\
\hline GDY-MoS ${ }_{2}$ nanosheets/CF & $\begin{array}{l}\text { Hydrothermal and deposi- } \\
\text { tion }\end{array}$ & $1.0 \mathrm{M} \mathrm{KOH}$ & $\begin{array}{l}10 \mathrm{~mA} \mathrm{~cm}^{-2} \text { at } 0.09 \mathrm{~V} \text { vs. } \\
\text { RHE }\end{array}$ & - & [111] \\
\hline $\mathrm{Mo}_{2} \mathrm{C} /$ graphene & Chemical vapor deposition & $0.5 \mathrm{M} \mathrm{H}_{2} \mathrm{SO}_{4}$ & $\begin{array}{l}10 \mathrm{~mA} \mathrm{~cm}^{-2} \text { at }-0.25 \mathrm{~V} \\
\text { vs. RHE }\end{array}$ & - & {$[183]$} \\
\hline $\mathrm{MoS}_{2} / \mathrm{Ti}_{3} \mathrm{C}_{2} @ \mathrm{C}$ & Etching and annealing & $0.5 \mathrm{M} \mathrm{H}_{2} \mathrm{SO}_{4}$ & $\begin{array}{l}10 \mathrm{~mA} \mathrm{~cm}^{-2} \text { at }-0.135 \mathrm{~V} \\
\text { vs. RHE }\end{array}$ & - & [119] \\
\hline
\end{tabular}

Some research groups demonstrated that the coupling of LDH nanosheets with nanocarbons apparently decreased the onset potential with respect to commercial $\mathrm{Ir} / \mathrm{C}$ catalyst and increased catalytic activity by providing the effective electrical pathway and high surface area [147-149]. Recently, Hou et al. developed a ternary $\mathrm{N}$-deficient porous $\mathrm{C}_{3} \mathrm{~N}_{4} / \mathrm{N}$-doped graphene/NiFe-LDHs (DPCN/NRGO/NiFe-LDHs) aerogel photoanode consisting of $\mathrm{N}$-deficient g- $_{3} \mathrm{~N}_{4}, \mathrm{~N}$-doped graphene, and NiFe-LDHs by a facile hydrothermal route for the efficient PEC-OER, as shown in Fig. 8a-c [150]. The layered DPCN and NiFe-LDH nanosheets were firstly synthesized through the pyrolysis of urea and liquid exfoliation process, respectively. Subsequently, the resulting DPCN and NiFe-LDH were mixed with RGO via a self-assembly process under hydrothermal conditions to form the DPCN/ NRGO/NiFe-LDH hybrid. The EDX spectroscopy demonstrated the $\mathrm{C}, \mathrm{N}, \mathrm{Ni}, \mathrm{Fe}$, and $\mathrm{O}$ are the principal elementals that exist in the DPCN/NRGO/NiFe-LDH structure, as presented in Fig. 8d. The HRTEM image further confirmed the intimate interfacial contacts among the three components shown in Fig. 8e. In this hybridized system, the introduced $3 \mathrm{D} \mathrm{N}$-doped graphene worked as an electron mediator to shuttle photogenerated charge carriers between $\mathrm{N}$-deficient $\mathrm{C}_{3} \mathrm{~N}_{4}$ and NiFe-LDHs, which resulted in the enhancement of separation and transfer efficiency of photogenerated charge carriers. The as-prepared DPCN/NRGO/NiFe-LDHs photoanode displayed an optimum configuration for PEC-OER by combining the advantages of each component with the merits of 3D aerogels. The photocurrent density of DPCN/ $\mathrm{NRGO/NiFe-LDHs} \mathrm{reached} 72.9 \mu \mathrm{A} \mathrm{cm}^{-2}$ at $1.22 \mathrm{~V}$ vs. RHE for OER under AM 1.5G irradiation, as presented in Fig. 8 , and the IPCE of $2.5 \%$ at $350 \mathrm{~nm}$.

In order to further accelerate the interfacial mass and electron transport in photoelectrodes during PEC-OER process, more carbon-containing systems have been recently developed. For example, Wu and co-workers utilized GDY as an excellent electron mediator [151]. The superhydrophilic 2D GDY photoelectrode was synthesized through an air plasma route. Subsequently, the superhydrophilic GDY was electrostatically combined with ultrathin CoAlLDH nanosheets. The 2D CoAl-LDH/GDY photoelectrode displayed an enhanced PEC-OER activity with an overpotential of $258 \mathrm{mV}$ at $10 \mathrm{~mA} \mathrm{~cm}{ }^{-2}$ and TOF of $0.60 \mathrm{~s}^{-1}$ at $300 \mathrm{mV}$. Meanwhile, the IPCE and photocurrent density of CoAl-LDH/GDY/BiVO 4 hybrid reached the highest value, $\sim 50 \%$ at $420 \mathrm{~nm}$ and $\sim 3.15 \mathrm{~mA} \mathrm{~cm}^{-2}$ at $1.23 \mathrm{~V}$ vs. RHE, respectively. The half-cell photoconversion efficiency of superhydrophilic CoAl-LDH/GDY combined with $\mathrm{BiVO}_{4}$ was evaluated, displaying a significant increase up to $0.63 \%$, by comparing with other GDY-free $\mathrm{LDH}-$ based $\mathrm{BiVO}_{4}$ photoanodes. Furthermore, DFT calculations indicated that the improvement in interfacial electron and mass transport was achieved through the utilization of superhydrophilic GDY, due to the strong interaction between GDY and CoAl-LDH, which is beneficial for absorbing water molecules around catalysts and boosting the PEC-OER activity. 

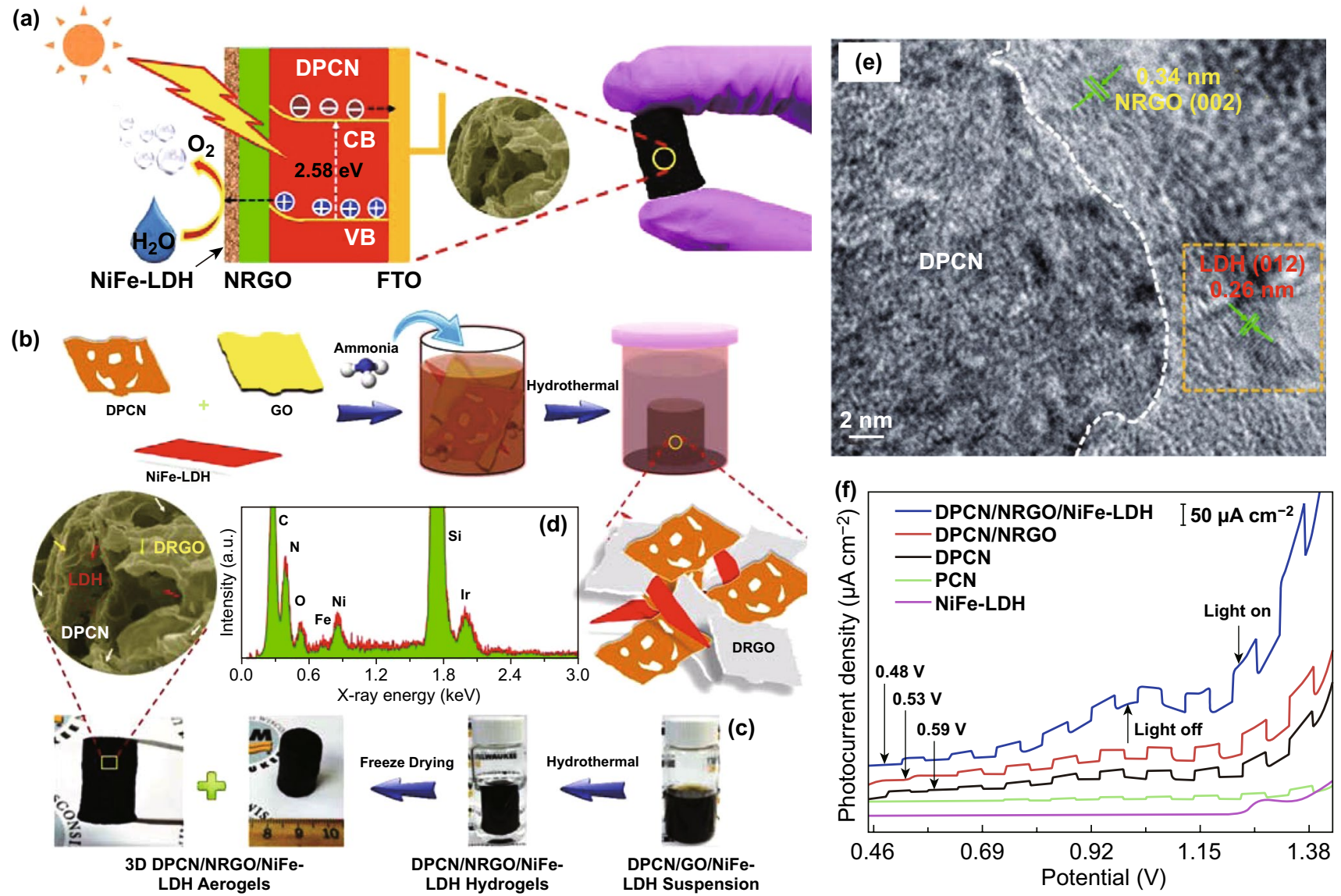

Fig. 8 a Illustration of PEC mechanism over synthesized 2D photoanode, b schematic fabrication process of DPCN/NRGO/NiFe-LDH, $\mathbf{c}$ pictures of the obtained aerogel samples, $\mathbf{d}$ EDX spectrum, and e HRTEM image of DPCN/NRGO/NiFe-LDHs, $\mathbf{f}$ photocurrent density vs. applied potential for PCN, DPCN, NiFe-LDH, DPCN/NRGO, DPCN/NRGO/NiFe-LDH under chopped AM 1.5G irradiation. Reproduced with permission from Ref. [150]. Copyright 2016 American Chemical Society

Based on the optimum PEC configurations, the nanocarbons/LDHs systems as active components are further utilized to integrate with other semiconductors, such as $\mathrm{TiO}_{2}$, $\mathrm{Cu}_{2} \mathrm{O}$, and $\mathrm{BiVO}_{4}$, for constructing high-quality three-component photoanodes [152-155]. For instance, Ning et al. reported a feasible strategy to construct a ternary hybridized PEC system by introducing RGO and NiFe-LDHs onto $\mathrm{TiO}_{2}$ nanorod arrays (NAs), which not only improved the separation and transport of the photogenerated charge carriers, but also increased the PEC-OER efficiency, as shown in Fig. 9e, f [156]. Firstly, $\mathrm{TiO}_{2}$ NAs were vertically grown on FTO substrate via a customized hydrothermal method, and then, layered RGO was deposited onto $\mathrm{TiO}_{2}$ NAs and annealed for strong adhesion. Subsequently, layered $\mathrm{NiFe}-\mathrm{LDH}$ was uniformly electrodeposited on the surface of $\mathrm{TiO}_{2} / \mathrm{RGO}$ NAs to fabricate a ternary $\mathrm{TiO}_{2} / \mathrm{rGO} / \mathrm{NiFe}-\mathrm{LDH}$ photoanode. The combined experimental and computational studies revealed that the added RGO was able to efficiently collect the photogenerated electrons from $\mathrm{TiO}_{2}$ owing to its high work function and fast electron mobility, as shown in Fig. 9d. As a result, the electron transport was enhanced, and NiFe-LDH functioned as an effective OER electrocatalyst.

Owing to this synergistic effect, the hybridized photoanode exhibited a significantly improved photocurrent density of $1.74 \mathrm{~mA} \mathrm{~cm}^{-2}$ at $0.6 \mathrm{~V}$ and photoconversion efficiency of $0.58 \%$ at $0.13 \mathrm{~V}$, which was superior to that of the $\mathrm{TiO}_{2}$-based photoanodes, as shown in Fig. 9a. Meanwhile, the estimated charge carrier separation and injection efficiencies of the hybridized system are presented in Fig. 9b, c. It was found that charge carrier separation efficiency of $98 \%$ at $0.6 \mathrm{~V}$ on $\mathrm{TiO}_{2} / \mathrm{RGO} / \mathrm{NiFe}-\mathrm{LDH}$ NAs was significantly enhanced as compared with $66 \%$ at $0.6 \mathrm{~V}$ on pristine $\mathrm{TiO}_{2}$ 
NAs. Meanwhile, the charge injection efficiency showed an apparent improvement for $\mathrm{TiO}_{2} / \mathrm{RGO} / \mathrm{NiFe}-\mathrm{LDH}$, achieving $95 \%$, with respect to $76 \%$ of bare $\mathrm{TiO}_{2} \mathrm{NAs}$, inferring a highly efficient PEC-OER activity. Moreover, ternary hybridized photoanode exhibited an average $\mathrm{O}_{2}$ evolution yield of $15.5 \mathrm{mmol} \mathrm{h}^{-1} \mathrm{~cm}^{-2}$ with the average Faradaic efficiency of $97 \%$, as displayed in Fig. 9g, which was 1.88 times higher than that of pristine $\mathrm{TiO}_{2} \mathrm{NAs}$.

This result further confirmed that the introduction of RGO and NiFe-LDH apparently promoted the PEC-OER activity with considerable stability under sunlight irradiation, where the photoinduced electrons transfer to the RGO from the conduction band of $\mathrm{TiO}_{2}$ and the holes to NiFe-LDH from the valence band of $\mathrm{TiO}_{2}$. Based on this effective strategy, Xiang and co-workers also reported an integration of rGOLDH-BiVO 4 by assembly of $2 \mathrm{D} \mathrm{BiVO}_{4}$ photoanode with CoAl-LDHs and graphene [157]. A remarkable improvement in the PEC-OER performance was obtained by this hybridized photoanode, compared with CoAl-LDH-BiVO and bare $\mathrm{BiVO}_{4}$ cases. The photocurrent density and IPCE
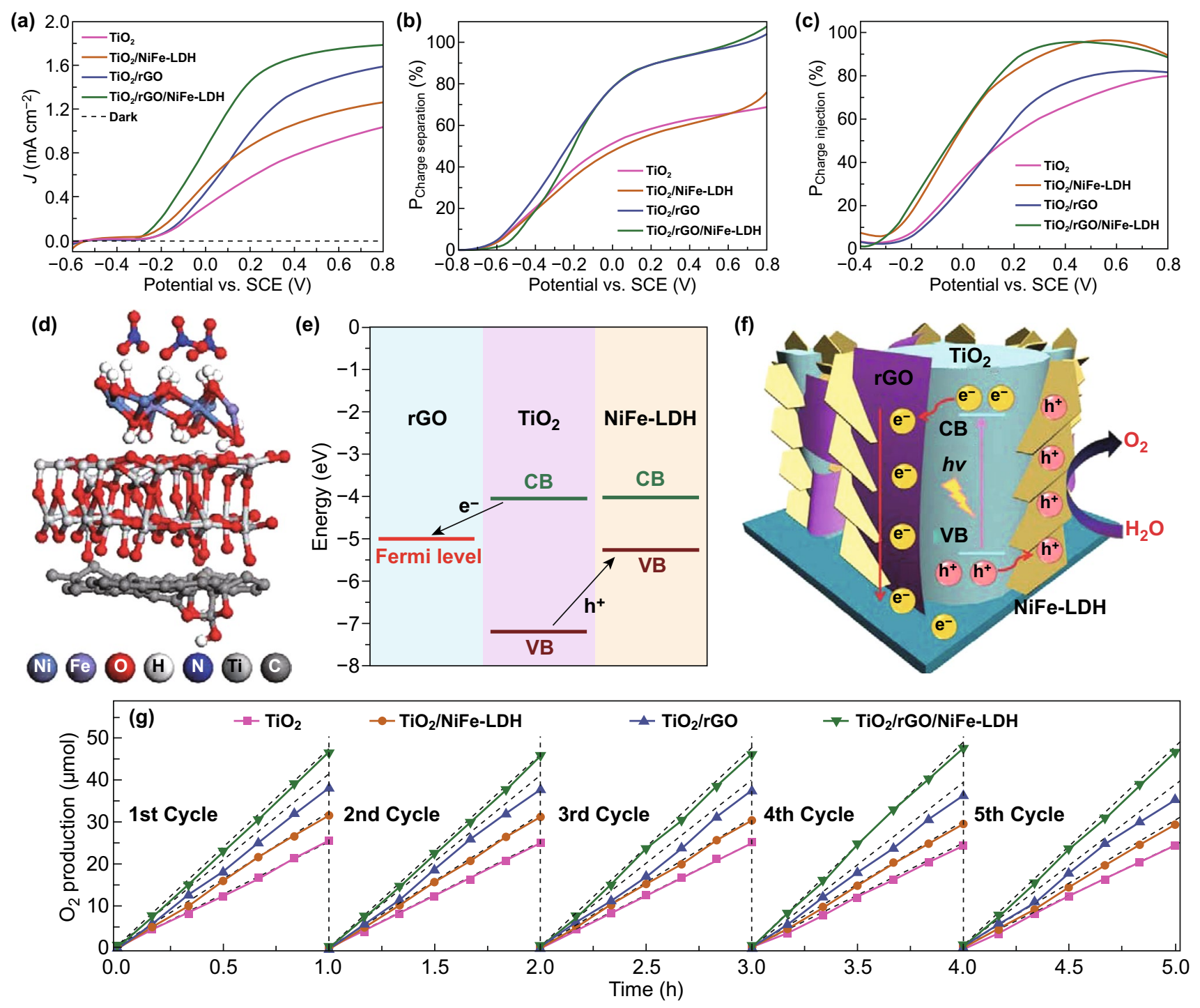

Fig. 9 a Current-potential curves, $\mathbf{b}$ charge separation, and $\mathbf{c}$ injection efficiencies vs. potential of $\mathrm{TiO}_{2}, \mathrm{TiO}_{2} / \mathrm{NiFe}-\mathrm{LDH}, \mathrm{TiO} / \mathrm{rGO}, \mathrm{TiO} / \mathrm{rGO} /$ $\mathrm{NiFe}-\mathrm{LDH}$ photoanodes, $\mathbf{d}$ optimized geometries of $\mathrm{TiO}_{2} / \mathrm{RGO} / \mathrm{NiFe}-\mathrm{LDH}, \mathbf{e}$ band alignments of $\mathrm{TiO}_{2}, \mathrm{RGO}$, and NiFe-LDH, $\mathbf{f}$ scheme of water oxidation process in hybridized $\mathrm{TiO}_{2} / \mathrm{rGO} / \mathrm{NiFe}-\mathrm{LDH}$ photoanode, $\mathbf{g}$ actual $\mathrm{O}_{2}$ evolution of $\mathrm{TiO}_{2}, \mathrm{TiO}_{2} / \mathrm{NiFe}-\mathrm{LDH}, \mathrm{TiO} / \mathrm{rGO}, \mathrm{TiO} / \mathrm{rGO} / \mathrm{NiFe}-$ $\mathrm{LDH}$ (the dot lines denote the theoretical $\mathrm{O}_{2}$ generation estimated from the measured photocurrent with Faradaic efficiency of $100 \%$ ). Reproduced with permission from Ref. [156]. Copyright 2016 Royal Society of Chemistry 
of rGO-LDH-BiVO 4 photoanode reached $2.13 \mathrm{~mA} \mathrm{~cm}^{-2}$ at $1.23 \mathrm{~V}$ vs. RHE and $52 \%$ at $400 \mathrm{~nm}$, which were 4.0 and 2.5 times higher compared to the pristine $\mathrm{BiVO}_{4}$ photoanode.

These results revealed that the enhancement of charge carriers separation efficiency and water oxidation kinetics could be mainly attributed to the introduction of $\mathrm{rGO}$ and $\mathrm{CoAl}-$ LDH. Similar as the above-mentioned $\mathrm{TiO}_{2} / \mathrm{RGO} / \mathrm{NiFe}-\mathrm{LDH}$ photoanode, such charge transfer pathways significantly shorten the carrier transportation distance and effectively suppress the carrier recombination. Consequently, the PEC-OER efficiency of the photoanode can be apparently enhanced by designing this triadic heterostructure.

On the other hand, CDs were used to substitute graphene to construct carbon-based NiFe-LDHs @ $\mathrm{BiVO}_{4}$ photoanode [158]. The introduction of CDs not only reduced the charge transfer resistance, but also lowered the overpotential for OER catalysis. As a result, ternary hybridized 2D photoanode exhibited the significantly enhanced photocurrent and IPCE value compared with the NiFe-LDH/ $\mathrm{BiVO}_{4}$. The IPCEs measured at $380 \mathrm{~nm}$ for $\mathrm{BiVO}_{4}, \mathrm{CDs} /$ $\mathrm{BiVO}_{4}, \mathrm{NiFe}-\mathrm{LDH} / \mathrm{BiVO}_{4}$, and $\mathrm{CDs} / \mathrm{NiFe}-\mathrm{LDH} / \mathrm{BiVO}_{4}$ were $19.17 \%, 22.97 \%, 24.59 \%$, and $40.94 \%$, respectively. Meanwhile, the $\mathrm{CDs} / \mathrm{NiFe}-\mathrm{LDH} / \mathrm{BiVO}_{4}$ hybridized photoanode had the highest conversion efficiency of $0.58 \%$ at $0.82 \mathrm{~V}$, outperforming the $\mathrm{NiFe}-\mathrm{LDH} / \mathrm{BiVO}_{4}$ catalyst with $0.34 \%$ at $0.91 \mathrm{~V}, \mathrm{CDs} / \mathrm{BiVO}_{4}$ with $0.17 \%$ at $0.99 \mathrm{~V}$, and pristine $\mathrm{BiVO}_{4}$ with $0.09 \%$ at $0.96 \mathrm{~V}$. Although the charge separation efficiency of $66.7 \%$ at $1.23 \mathrm{~V}$ for $\mathrm{CDs} / \mathrm{NiFe}-\mathrm{LDH} / \mathrm{BiVO}_{4}$ had no noticeable improvement compared to other photoanodes, the charge injection efficiency was notably enhanced from 69.2 to $92.8 \%$ at $1.23 \mathrm{~V}$.

These data clearly suggest that the improved catalytic activity was due to the reduced OER overpotential and the enhanced charge transport kinetics. When the photoinduced holes accumulate at the surface of LDHs, the overpotential of OER at the solid-liquid interface depends on the energy barrier and reaction rate. As a result, the decreased OER overpotential could significantly improve the PER-OER activities.

\subsection{Layered Bismuth Oxyhalides (LBOs)}

Apart from the 2D LDHs for PEC-OER catalysis, most of the photoanodes have been made of semiconducting metal oxides due to the apparent chemical stability and facile fabrication processes, which are important factors for practical large-scale applications. Therefore, 2D metal oxides with the broad photoresponse spectrum and high absorption efficiency are typically chosen as light absorbers to optimize the PEC water splitting. Among various semiconducting metal oxides, ternary metal oxides attract more and more attention as efficient photoanodes involved in a PEC system for efficient OER [159].

Commonly, ternary metal oxide is often defined as an oxide matrix consisting of two different metal ions. Compared with binary oxides, such as $\mathrm{TiO}_{2}$ [160], $\mathrm{ZnO}$ [161], and $\mathrm{WO}_{3}[162,163]$, ternary metal oxides possess rich and tunable compositions, which leads to controllable atomic and electronic structures as photoelectrodes with tunable light absorption [164, 165]. In previous reviews [166-168], ternary $\mathrm{BiVO}_{4}$-related photoelectrodes have been summarized and discussed; hence, $2 \mathrm{D} \mathrm{BiVO}_{4}$ as a common supporting material in PEC systems is not discussed further.

Compared with conventional $\mathrm{BiVO}_{4}$-based photoanodes, ternary layered bismuth oxyhalides have variable layer thickness, suitable band alignments accompanied with tunable chemical compositions, and highly exposed dangling bonds as active sites for water splitting [169-171]. Generally, layered bismuth oxyhalides, $\mathrm{BiOX}(\mathrm{X}=\mathrm{Cl}, \mathrm{Br}, \mathrm{I})$, are a family of ternary V-VI-VII semiconductors with a tetragonal matlockite crystal structure and atomic composition-related bandgap energy, where a layered nanostructure is constituted by stacked [X-Bi-O-Bi-X] slabs via van der Waals interactions, as shown in Fig. 10a, b [172, 173]. In this model, one bismuth atom is surrounded by four oxygen atoms and four halogen atoms, forming an asymmetric decahedral. The interlayer van der Waals attraction arising through the strong covalent bonding between the layers creates more interesting properties in the fields of anisotropic structures, electrics, and optics [174]. Zhang and co-workers reported BiOI nanoplates as a new 2D material for assembling solar cells by encapsulating $\mathrm{BiOI}$ into chitosan, which displayed a promising PEC activity, as shown in Fig. 10c [175]. Since then, layered $\mathrm{BiOI}$ and similar materials have been widely used in photoelectrodes for water splitting and environmental remediation [176-178].

To further enhance the PEC performance of layered bismuth oxyhalides-based photoelectrodes, nanocarbons have been utilized to enhance the conductivity, which is 

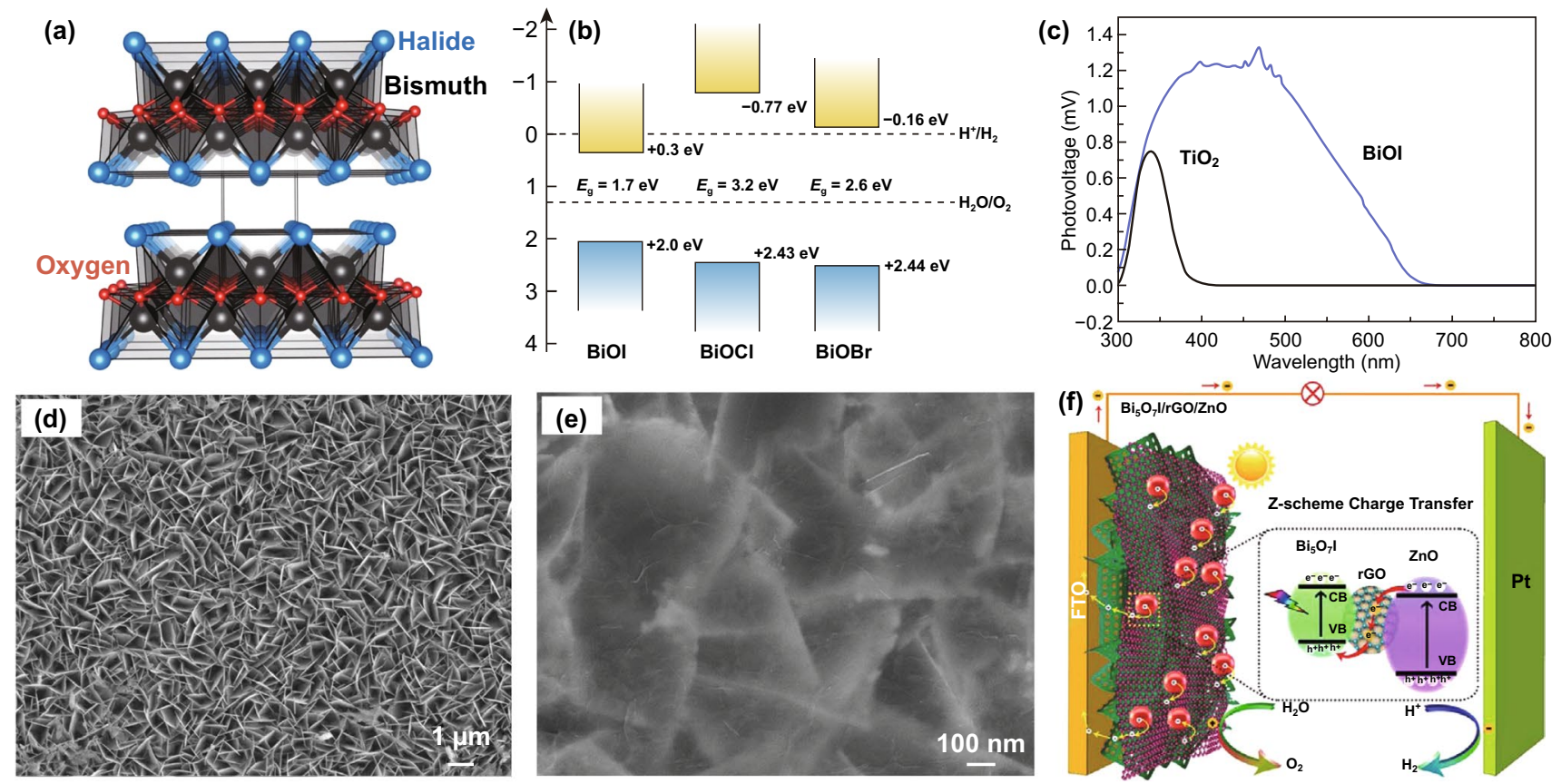

Fig. 10 a Crystal structure of bismuth oxyhalide systems, $\mathbf{b}$ band alignments of $\mathrm{BiOX}$ at $\mathrm{pH}=0$, $\mathbf{c}$ surface photovoltaic spectroscopies of BiOI and $\mathrm{TiO}_{2}$, d, e SEM images of porous $\mathrm{Bi}_{5} \mathrm{O}_{7} \mathrm{I}$ and $\mathrm{Bi}_{5} \mathrm{O}_{7} \mathrm{I} / \mathrm{rGO} / \mathrm{ZnO}$, f scheme of charge transfer mechanism of $\mathrm{Bi}_{5} \mathrm{O}_{7} \mathrm{I} / \mathrm{rGO} / \mathrm{ZnO}$. $\mathrm{Reproduced}$ with permission from Ref. [173, 175, 179]. Copyright 2016 Royal Society of Chemistry, Copyright 2009 and 2019 Elsevier

beneficial for fast movement of photogenerated charge carriers and effective suppression of recombination. For example, Jiao et al. used bismuth oxyiodide to assemble the $\mathrm{Bi}_{5} \mathrm{O}_{7} \mathrm{I}$ nanosheets/RGO/ZnO heterojunction by depositing $\mathrm{ZnO}$ QDs/RGO on the surface of $\mathrm{Bi}_{5} \mathrm{O}_{7} \mathrm{I}$ nanosheets (Fig. 10f) [179]. Firstly, porous $\mathrm{Bi}_{5} \mathrm{O}_{7} \mathrm{I}$ nanosheets enriched with $\mathrm{O}$ vacancies were prepared through a reductive calcination of BiOI (Fig. 10d), which facilitated light harvesting as well as separation and transportation of photogenerated charge carriers. Further, ZnO QDs/RGO was deposited on the 2D $\mathrm{Bi}_{5} \mathrm{O}_{7} \mathrm{I}$ photoanode to form a heterojunction, as presented in Fig. 10e. Under light illumination, the photoinduced electrons on the conduction band of $\mathrm{ZnO}$ could transfer to the valence band of $\mathrm{Bi}_{5} \mathrm{O}_{7} \mathrm{I}$ via $\mathrm{RGO}$ nanosheets, thus leading to the quenching of photoexcited holes at $\mathrm{Bi}_{5} \mathrm{O}_{7} \mathrm{I}$. Therefore, the effects not only help to improve the efficient separation of photogenerated electron-hole pairs, but also maintain the original excellent PEC redox ability. Consequently, a high PEC-OER performance was achieved over $\mathrm{Bi}_{5} \mathrm{O}_{7} \mathrm{I} / \mathrm{RGO} /$
$\mathrm{ZnO}$ heterojunction with photocurrent density of $15 \mu \mathrm{A}$ $\mathrm{cm}^{-2}$, which was the highest value among all the prepared $\mathrm{Bi}_{5} \mathrm{O}_{7} \mathrm{I}$-based samples.

We articulate that the studies on integration of 2D BiOX photoelectrodes with nanocarbons for PEC water splitting are still at initial stage. In the future, the investigation on utilizing nanocarbons to modify $2 \mathrm{D} \mathrm{BiOX}$ is necessary for constructing $2 \mathrm{D}$ integrated photoelectrodes. At the same time, various design strategies regrading solar-driven photocatalysts, such as tuning localized surface nanostructures [180], exposing efficient surfaces of photogenerated charge carriers transfer [181], and introducing desirable components [182] in 2D BiOX photoelectrodes, may offer new paths to improve charge carrier transport between the nanocarbons and 2D BiOX, reduce redox HER/OER potentials, thereby further increasing the solar harvesting efficiency. These representative LDHs- and LBO-based 2D photoanodes with nanocarbons for PEC-OER are summarized in Table 2. 
Table 2 Comparison of PEC-OER activity of various 2D photoanodes

\begin{tabular}{|c|c|c|c|c|}
\hline Photoanodes & Synthesis method & Electrolyte & IPCE & References \\
\hline DPCN/NRGO/NiFe-LDH & $\begin{array}{l}\text { Pyrolysis and hydrother- } \\
\text { mal }\end{array}$ & $\begin{array}{r}0.01 \mathrm{M} \mathrm{Na}_{2} \mathrm{SO}_{4}, \mathrm{pH}=6.872 .9 \mu \mathrm{A} \mathrm{cm}^{-2} \\
\text { at } 1.22 \mathrm{~V} \text { vs. RHE }\end{array}$ & $2.5 \%$ at $350 \mathrm{~nm}$ & {$[150]$} \\
\hline $\mathrm{CoAl}-\mathrm{LDH} / \mathrm{GDY} / \mathrm{BiVO}_{4}$ & $\begin{array}{l}\text { Air plasma and wet depo- } \\
\text { sition }\end{array}$ & $\begin{array}{c}0.1 \mathrm{M} \mathrm{Na}_{2} \mathrm{SO}_{4}, \mathrm{pH}=6.83 .15 \mathrm{~mA} \mathrm{~cm}^{-2} \text { at } 1.23 \mathrm{~V} \\
\text { vs. RHE }\end{array}$ & $\sim 50 \%$ at $420 \mathrm{~nm}$ & {$[151]$} \\
\hline $\mathrm{BiVO}_{4} / \mathrm{RGO} / \mathrm{NiFe}-\mathrm{LDH}$ & $\begin{array}{l}\text { Electrodeposition and } \\
\text { annealing }\end{array}$ & $\begin{array}{l}0.1 \mathrm{M} \text { phosphate buffer } 1.13 \mathrm{~mA} \mathrm{~cm}^{-2} \text { at } 1.23 \mathrm{~V} \\
\text { saline, } \mathrm{pH}=7\end{array}$ & $51.08 \%$ at $420 \mathrm{~nm}$ & {$[152]$} \\
\hline $\mathrm{TiO}_{2} / \mathrm{RGO} / \mathrm{NiFe}-\mathrm{LDH}$ & $\begin{array}{l}\text { Hydrothermal and spin } \\
\text { coating and electrochem- } \\
\text { ical deposition }\end{array}$ & $\begin{array}{c}0.5 \mathrm{M} \mathrm{Na}_{2} \mathrm{SO}_{4}, \mathrm{pH}=6.81 .74 \mathrm{~mA} \mathrm{~cm}^{-2} \text { at } 1.25 \mathrm{~V} \\
\text { vs. RHE }\end{array}$ & $5.12 \%$ at $400 \mathrm{~nm}$ & {$[156]$} \\
\hline RGO/CoAl-LDH/BiVO ${ }_{4}$ & Hydrothermal & $\begin{array}{l}0.1 \mathrm{M} \text { phosphate buffer } 2.13 \mathrm{~mA} \mathrm{~cm}^{-2} \text { at } 1.23 \mathrm{~V} \\
\text { saline, } \mathrm{pH}=7\end{array}$ & $52 \%$ at $400 \mathrm{~nm}$ & {$[157]$} \\
\hline $\mathrm{CDs} / \mathrm{NiFe}-\mathrm{LDH} / \mathrm{BiVO}_{4}$ & $\begin{array}{l}\text { Electrochemical deposi- } \\
\text { tion }\end{array}$ & $\begin{array}{l}0.5 \mathrm{M} \text { phosphate buffer } 1.49 \mathrm{~mA} \mathrm{~cm}^{-2} \text { at } 1.23 \mathrm{~V} \\
\text { saline, } \mathrm{pH}=7\end{array}$ & $40.94 \%$ at $380 \mathrm{~nm}$ & {$[158]$} \\
\hline $\mathrm{Bi}_{5} \mathrm{O}_{7} \mathrm{I} / \mathrm{RGO} / \mathrm{ZnO}$ & $\begin{array}{l}\text { Annealing and wet deposi- } \\
\text { tion }\end{array}$ & $\begin{array}{c}0.1 \mathrm{MNa}_{2} \mathrm{SO}_{4}, \mathrm{pH}=6.80 .21 \mathrm{~mA} \mathrm{~cm}-2 \\
\mathrm{SCE}\end{array}$ & - & [179] \\
\hline
\end{tabular}

\section{Conclusion and Perspectives}

In summary, we have critically reviewed recent developments regarding rational PEC configurations consisting of photoelectrodes, interlayers, and co-catalysts to achieve sunlight harvesting in a broad spectral range, efficient separation and transfer of photogenerated charge carriers, as well as rapid reaction kinetics for water splitting. To achieve all these criteria, elaborately designed 2D photoelectrodes have been widely utilized, including GCN, TMDs, and MXene for PEC-HER, LDHs and LBOs for PEC-OER. These materials are promising for solar-driven water splitting in PEC systems. Following the effective optimization principles, metal-free nanocarbons, such as 0D CDs, 1D CNTs, 2D graphene, and 2D GDYs, have been used as electron mediators to improve the separation and transport efficiencies of photogenerated charge carriers in high-performance PEC systems for water splitting. Meanwhile, the state of the art in the synthesis and characterizations of 2D photoelectrodes hybridized with nanocarbons for superior efficiencies in PEC water splitting has been critically reviewed.

In this context, GCN material is widely studied as a $2 \mathrm{D}$ photoelectrode due to its unique layered structure, suitable bandgap, and a suitable negative conduction band for HER. In this application, the GCN not only acts as a supporting material to harvest solar energy, but also functions as an effective electrocatalyst to drive electrocatalytic HER. To improve PEC-HER performance, 2D graphene and OD $\mathrm{CDs}$ are frequently introduced into the GCN to enhance the separation and transport efficiency of photogenerated charge carriers. Similar to 2D GCN, when used alone, 2D TMD (especially $\mathrm{MoS}_{2}$ ) HER catalysts also face poor separation and severe recombination of photogenerated charge carriers.

To overcome these problems, a series of nanocarbons, such as graphene or CNTs, with high charge mobility as co-catalysts have been introduced to assemble 2D photocathodes, which exhibit a significant enhancement in PEC-HER performance. Furthermore, although the emerging 2D MXenes possesses metallic conductivities and highly exposed metal sites, which present the strong redox activity for HER, the separation and transport efficiencies of the photogenerated charge carriers still require substantial improvement. Therefore, nanocarbons, such as CNTs, as co-catalysts and electron mediators are introduced into 2D MXenes to promote the charge carrier separation and transfer in 2D photocathodes for the enhanced PEC-HER activity under light illumination.

Apart from the above-mentioned 2D GCN, TMDs, and MXenes for efficient HER, 2D LDHs have been explored as $\mathrm{Ru}$ or Ir-free photoelectrodes for obtaining high PEC-OER activity because the LDHs materials contain transition metals of $\mathrm{Fe}, \mathrm{Co}$, and $\mathrm{Ni}$. These metals facilitate PEC-OER with relatively low overpotentials, thereby accelerating water splitting. Importantly, 2D LDH materials possess tunable chemical composition by varying the ratios of different cations, porous nanostructures with large specific surface area, highly exposed active sites with high catalytic reaction rates, as well as high structural stability. Based on these merits, diverse LDHs-based 2D photoanodes utilizing nanocarbons 
have been analyzed, which show significant performance improvement in PEC water splitting in comparison with bare LDHs photoanodes.

Meanwhile, bismuth oxyhalides (e.g., BiOI) are often used as effective light absorbers for PEC-OER. Since semiconducting bismuth oxyhalides have a sufficiently positive valence band, the photoinduced holes with strong oxidative abilities can effectively oxidize water to produce $\mathrm{O}_{2}$. Therefore, these bismuth oxyhalides are combined with layered nanocarbons (e.g., graphene and GDY) as co-catalysts to form hybridized photoanodes, eventually achieving the expected improvement in the PEC-OER performance.

Although remarkable advances have been made to enhance the PEC-HER and PEC-OER performances by coupling 2D photoelectrodes with nanocarbon co-catalysts, up to now, the roles of 2D support materials and nanocarbons in heterostructured photoelectrodes are not fully understood due to the lack of strong experimental evidences and sufficient theoretical insights. Therefore, comprehensive understanding of the reactive mechanisms is a viable path to design and fabricate high-performance 2D integrated photoelectrodes for water splitting. Besides, the charge carrier dynamics in PEC system should be further uncovered based on a series of PEC tools, such as IMPS/IMVS, TAS, TRPL, and EIS. Meanwhile, a combination of advanced in situ techniques, for instance, in situ XPS, in situ TEM, and in situ $\mathrm{X}$-ray absorption spectrum (XAS), should be used to reveal correlations between structure and PEC performance.

On the other hand, due to the limitations of the available experimental technologies, there is an urgent need to develop reliable theoretical models and simulations to explain the optimized PEC system with 2D photoelectrodes by utilizing artificial intelligence, high-performance computing, and/or big data analytics. Meanwhile, it is useful to further advance the visualization of photogenerated charge carriers inside 2D photoelectrodes based on simulation software and scanning tunneling microscope (STM) and further optimize the configuration of PEC systems.

Nowadays, direct comparisons of PEC-HER/OER performances among the many different nanocarbons-enhanced photoelectrodes are quite challenging because of the different compositions, amounts, and test parameters, which significantly affect the PEC results. It is required that the test principles and conditions of PEC-HER/OER should be unified in the future. Furthermore, the fabrication procedures of $2 \mathrm{D}$ photoelectrodes and nanocarbons are the key determinants of the final water splitting efficiencies. Therefore, it is necessary to develop several feasible and unified synthetic protocols, such as electrochemical or hydrothermal routes for better comparison and finding the optimal material system. This approach is promising to translate the laboratory-scale research into the widespread commercial applications of the PEC-HER and PEC-OER processes.

Acknowledgements Y. Hou thanks the support from the National Natural Science Foundation of China (21878271, 51702284, 21878270, and 21961160742), the Zhejiang Provincial Natural Science Foundation of China (LR19B060002), the Fundamental Research Funds for the Central Universities, the Startup Foundation for Hundred-Talent Program of Zhejiang University, the Leading Innovative and Entrepreneur Team Introduction Program of Zhejiang (2019R01006), Key Laboratory of Marine Materials and Related Technologies, CAS, and Zhejiang Key Laboratory of Marine Materials and Protective Technologies (2020K10). J. Ke thanks the support of the NSFC 21501138, the Natural Science Foundation of Hubei Province (2019CFB556), and Science Research Foundation of Wuhan Institute of Technology (K2019039). K.O. thanks the Australian Research Council (ARC) and QUT Centre for Materials Science for partial support.

Open Access This article is licensed under a Creative Commons Attribution 4.0 International License, which permits use, sharing, adaptation, distribution and reproduction in any medium or format, as long as you give appropriate credit to the original author(s) and the source, provide a link to the Creative Commons licence, and indicate if changes were made. The images or other third party material in this article are included in the article's Creative Commons licence, unless indicated otherwise in a credit line to the material. If material is not included in the article's Creative Commons licence and your intended use is not permitted by statutory regulation or exceeds the permitted use, you will need to obtain permission directly from the copyright holder. To view a copy of this licence, visit http://creativecommons.org/licenses/by/4.0/.

\section{References}

1. A. Fujishima, K. Honda, Electrochemical photolysis of water at a semiconductor electrode. Nature 238, 37-38 (1972). https ://doi.org/10.1038/238037a0

2. J. Low, J. Yu, M. Jaroniec, S. Wageh, A.A. Al-Ghamdi, Heterojunction photocatalysts. Adv. Mater. 29(20), 1601694 (2017). https://doi.org/10.1002/adma.201601694

3. Q. Xu, L. Zhang, J. Yu, S. Wageh, A.A. Al-Ghamdi et al., Direct Z-scheme photocatalysts: principles, synthesis, and applications. Mater. Today 21(10), 1042-1063 (2018). https ://doi.org/10.1016/j.mattod.2018.04.008

4. T. Hisatomi, J. Kubota, K. Domen, Recent advances in semiconductors for photocatalytic and photoelectrochemical water splitting. Chem. Soc. Rev. 43(22), 7520-7535 (2014). https ://doi.org/10.1039/c3cs60378d 
5. I. Roger, M.A. Shipman, M.D. Symes, Earth-abundant catalysts for electrochemical and photoelectrochemical water splitting. Nat. Rev. Chem. 1, 0003 (2017). https://doi. org/10.1038/s41570-016-0003

6. W.H. Wang, Y. Himeda, J.T. Muckerman, G.F. Manbeck, E. Fujita, $\mathrm{CO}_{2}$ hydrogenation to formate and methanol as an alternative to photo- and electrochemical $\mathrm{CO}_{2}$ reduction. Chem. Rev. 115(23), 12936-12973 (2015). https://doi. org/10.1021/acs.chemrev.5b00197

7. C. Lu, J. Yang, S. Wei, S. Bi, Y. Xia et al., Atomic Ni anchored covalent triazine framework as high efficient electrocatalyst for carbon dioxide conversion. Adv. Funct. Mater. 29(10), 1806884 (2019). https://doi.org/10.1002/adfm.20180 6884

8. M. Ali, F. Zhou, K. Chen, C. Kotzur, C. Xiao et al., Nanostructured photoelectrochemical solar cell for nitrogen reduction using plasmon-enhanced black silicon. Nat. Commun. 7, 11335 (2016). https://doi.org/10.1038/ncomms11335

9. L.L. Yu, J.Z. Qin, W.J. Zhao, Z.G. Zhang, J. Ke et al., Advances in two-dimensional MXenes for nitrogen electrocatalytic reduction to ammonia. Int. J. Photoenergy 2020, 1-11 (2020). https://doi.org/10.1155/2020/5251431

10. X. Zou, C. Yuan, Y. Dong, H. Ge, J. Ke et al., Lanthanum orthovanadate/bismuth oxybromide heterojunction for enhanced photocatalytic air purification and mechanism exploration. Chem. Eng. J. 379, 122380 (2020). https://doi. org/10.1016/j.cej.2019.122380

11. J. Ke, H.R. Zhou, Y.Y. Peng, D.Y. Tang, In-situ construction of a two-dimensional heterojunction by stacking bismuth trioxide nanoplates with reduced graphene oxide for enhanced water oxidation performance. J. Nanosci. Nanotechnol. 19(9), 5554-5561 (2019). https://doi.org/10.1166/jnn.2019.16568

12. C. Lei, Y. Wang, Y. Hou, P. Liu, J. Yang et al., Efficient alkaline hydrogen evolution on atomically dispersed $\mathrm{Ni}-\mathrm{N}_{x}$ species anchored porous carbon with embedded Ni nanoparticles by accelerating water dissociation kinetics. Energy Environ. Sci. 12(1), 149-156 (2019). https://doi.org/10.1039/C8EE0 $1841 \mathrm{C}$

13. H. Xie, J. Zhang, D. Wang, J. Liu, L. Wang et al., Construction of three-dimensional g- $\mathrm{C}_{3} \mathrm{~N}_{4}$ /attapulgite hybrids for $\mathrm{Cd}(\mathrm{II})$ adsorption and the reutilization of waste adsorbent. Appl. Surf. Sci. 504, 144456 (2020). https://doi. org/10.1016/j.apsusc.2019.144456

14. J. Liu, Y. Li, J. Ke, Z. Wang, H. Xiao, Synergically improving light harvesting and charge transportation of $\mathrm{TiO}_{2}$ nanobelts by deposition of $\mathrm{MoS}_{2}$ for enhanced photocatalytic removal of Cr(VI). Catalysts 7(12), 30 (2017). https://doi.org/10.3390/ catal7010030

15. Z. Cai, X. Bu, P. Wang, J.C. Ho, J. Yang et al., Recent advances in layered double hydroxide electrocatalysts for the oxygen evolution reaction. J. Mater. Chem. A 7(10), 5069-5089 (2019). https://doi.org/10.1039/c8ta11273h

16. D. Yang, G. Yang, J. Li, S. Gai, F. He et al., NIR-driven water splitting by layered bismuth oxyhalide sheets for effective photodynamic therapy. J. Mater. Chem. B 5(22), 4152-4161 (2017). https://doi.org/10.1039/c7tb00688h
17. J. Qin, X. Hu, X. Li, Z. Yin, B. Liu et al., 0D/2D $\mathrm{AgInS}_{2} /$ MXene Z-scheme heterojunction nanosheets for improved ammonia photosynthesis of $\mathrm{N}_{2}$. Nano Energy 61, 27-35 (2019). https://doi.org/10.1016/j.nanoen.2019.04.028

18. W. Zheng, J. Yang, H. Chen, Y. Hou, Q. Wang et al., Atomically defined undercoordinated active sites for highly efficient $\mathrm{CO}_{2}$ electroreduction. Adv. Funct. Mater. 30(4), 1907658 (2019). https://doi.org/10.1002/adfm.201907658

19. J. Yang, D. Wang, H. Han, C. Li, Roles of cocatalysts in photocatalysis and photoelectrocatalysis. Acc. Chem. Res. 46(8), 1900-1909 (2013). https://doi.org/10.1021/ar300227e

20. X. Chang, T. Wang, P. Yang, G. Zhang, J. Gong, The development of cocatalysts for photoelectrochemical $\mathrm{CO}_{2}$ reduction. Adv. Mater. 31(31), 1804710 (2019). https://doi.org/10.1002/ adma.201804710

21. S. Zhong, Y. Xi, S. Wu, Q. Liu, L. Zhao et al., Hybrid cocatalysts in semiconductor-based photocatalysis and photoelectrocatalysis. J. Mater. Chem. A 8(30), 14863-14894 (2020). https://doi.org/10.1039/d0ta04977h

22. D. Chen, Z. Liu, Z. Guo, M. Ruan, W. Yan, 3D branched $\mathrm{Ca}-\mathrm{Fe}_{2} \mathrm{O}_{3} / \mathrm{Fe}_{2} \mathrm{O}_{3}$ decorated with $\mathrm{Pt}$ and Co-Pi: Improved charge-separation dynamics and photoelectrochemical performance. Chemsuschem 12(14), 3286-3295 (2019). https ://doi.org/10.1002/cssc.201901331

23. W. Xu, W. Tian, L. Meng, F. Cao, L. Li, Ion sputteringassisted double-side interfacial engineering for CdIn2S4 photoanode toward improved photoelectrochemical water splitting. Adv. Mater. Interfaces 7(6), 1901947 (2020). https ://doi.org/10.1002/admi.201901947

24. H. Li, P. Wen, D.S. Itanze, M.W. Kim, S. Adhikari et al., Phosphorus-rich colloidal cobalt diphosphide $\left(\mathrm{CoP}_{2}\right)$ nanocrystals for electrochemical and photoelectrochemical hydrogen evolution. Adv. Mater. 31(24), 1900813 (2019). https://doi.org/10.1002/adma.201900813

25. L. Badia-Bou, E. Mas-Marza, P. Rodenas, E.M. Barea, F. Fabregat-Santiago et al., Water oxidation at hematite photoelectrodes with an iridium-based catalyst. J. Phys. Chem. C 117(8), 3826-3833 (2013). https://doi.org/10.1021/jp311 $983 n$

26. M. Zhong, T. Hisatomi, Y. Kuang, J. Zhao, M. Liu et al., Surface modification of $\mathrm{CoO}_{x}$ loaded $\mathrm{BiVO}_{4}$ photoanodes with ultrathin p-type $\mathrm{NiO}$ layers for improved solar water oxidation. J. Am. Chem. Soc. 137(15), 5053-5060 (2015). https://doi.org/10.1021/jacs.5b00256

27. T.A. Kandiel, M.G. Ahmed, A.Y. Ahmed, Physical insights into band bending in pristine and Co-Pi-modified $\mathrm{BiVO}_{4}$ photoanodes with dramatically enhanced solar water splitting efficiency. J. Phys. Chem. Lett. 11(13), 5015-5020 (2020). https://doi.org/10.1021/acs.jpclett.0c01419

28. Y. Wang, W. Tian, F. Cao, D. Fang, S. Chen et al., Boosting PEC performance of Si photoelectrodes by coupling bifunctional CuCo hybrid oxide cocatalysts. Nanotechnology 29(42), 425703 (2018). https://doi.org/10.1088/1361-6528/ aad $7 \mathrm{a} 0$

29. Y. Wang, W. Tian, C. Chen, W. Xu, L. Li, Tungsten trioxide nanostructures for photoelectrochemical water splitting: 
material engineering and charge carrier dynamic manipulation. Adv. Funct. Mater. 29(23), 1809036 (2019). https://doi. org/10.1002/adfm.201809036

30. C. Lei, Z. Wen, S. Lyu, J. Si, B. Yang et al., Nanostructured carbon based heterogeneous electrocatalysts for oxygen evolution reaction in alkaline media. ChemCatChem 11(24), 5855-5874 (2019). https://doi.org/10.1002/cctc.201901707

31. Y. Hou, M. Qiu, M.G. Kim, P. Liu, G. Nam et al., Atomically dispersed nickel-nitrogen-sulfur species anchored on porous carbon nanosheets for efficient water oxidation. Nat. Commun. 10, 1392 (2019). https://doi.org/10.1038/s41467-01909394-5

32. Y. He, X. Zhuang, C. Lei, L. Lei, Y. Hou et al., Porous carbon nanosheets: synthetic strategies and electrochemical energy related applications. Nano Today 24, 103-119 (2019). https ://doi.org/10.1016/j.nantod.2018.12.004

33. L. Wang, J. Cao, X. Cheng, C. Lei, Q. Dai et al., ZIF-derived carbon nanoarchitecture as a bifunctional $\mathrm{pH}$-universal electrocatalyst for energy-efficient hydrogen evolution. ACS Sustainable Chem. Eng. 7(11), 10044-10051 (2019). https://doi. org/10.1021/acssuschemeng.9b01315

34. N. Liu, W. Huang, X. Zhang, L. Tang, L. Wang et al., Ultrathin graphene oxide encapsulated in uniform MIL$88 \mathrm{~A}(\mathrm{Fe})$ for enhanced visible light-driven photodegradation of RhB. Appl. Catal. B: Environ. 221, 119-128 (2018). https ://doi.org/10.1016/j.apcatb.2017.09.020

35. Y. Li, L. Xu, H. Liu, Y. Li, Graphdiyne and graphyne: from theoretical predictions to practical construction. Chem. Soc. Rev. 43(8), 2572-2586 (2014). https://doi.org/10.1039/c3cs6 $0388 \mathrm{a}$

36. M. Inagaki, F. Kang, Graphene derivatives: graphane, fluorographene, graphene oxide, graphyne and graphdiyne. J. Mater. Chem. A 2(33), 13193-13206 (2014). https://doi. org/10.1039/c4ta01183j

37. Y. Hou, M. Qiu, T. Zhang, J. Ma, S. Liu et al., Efficient electrochemical and photoelectrochemical water splitting by a 3D nanostructured carbon supported on flexible exfoliated graphene foil. Adv. Mater. 29(3), 1604480 (2017). https:// doi.org/10.1002/adma.201604480

38. F. Bi, X. Zhang, J. Chen, Y. Yang, Y. Wang, Excellent catalytic activity and water resistance of UiO-66-supported highly dispersed Pd nanoparticles for toluene catalytic oxidation. Appl. Catal. B: Environ. 269, 118767 (2020). https:// doi.org/10.1016/j.apcatb.2020.118767

39. Q. Pan, H. Liu, Y. Zhao, S. Chen, B. Xue et al., Preparation of N-graphdiyne nanosheets at liquid/liquid interface for photocatalytic NADH regeneration. ACS Appl. Mater. Interfaces 11(3), 2740-2744 (2019). https://doi.org/10.1021/ acsami.8b03311

40. S. Thangavel, K. Krishnamoorthy, V. Krishnaswamy, N. Raju, S.J. Kim et al., Graphdiyne-ZnO nanohybrids as an advanced photocatalytic material. J. Phys. Chem. C 119(38), 22057-22065 (2015). https://doi.org/10.1021/acs.jpcc.5b061 38

41. Y. Fang, Y. Xue, L. Hui, H. Yu, Y. Liu et al., In situ growth of graphdiyne based heterostructure: toward efficient overall water splitting. Nano Energy 59, 591-597 (2019). https://doi. org/10.1016/j.nanoen.2019.03.022

42. X. Zou, Y. Dong, S. Li, J. Ke, Y. Cui, Facile anion exchange to construct uniform $\mathrm{AgX}(\mathrm{X}=\mathrm{Cl}, \mathrm{Br}, \mathrm{I}) / \mathrm{Ag} 2 \mathrm{CrO} 4 \mathrm{NR}$ hybrids for efficient visible light driven photocatalytic activity. Sol. Energy 169, 392-400 (2018). https://doi.org/10.1016/j.solen er.2018.05.017

43. M.A. Younis, S. Lyu, Q. Zhao, C. Lei, P. Zhang et al., Noble metal-free two dimensional carbon-based electrocatalysts for water splitting. BMC Mater. 1(1), 6 (2019). https://doi. org/10.1186/s42833-019-0006-2

44. C. Lei, H. Chen, J. Cao, J. Yang, M. Qiu et al., Fe-N $\mathrm{N}_{4}$ sites embedded into carbon nanofiber integrated with electrochemically exfoliated graphene for oxygen evolution in acidic medium. Adv. Energy Mater. 8(26), 1801912 (2018). https:// doi.org/10.1002/aenm.201801912

45. T. Wang, Q. Zhao, Y. Fu, C. Lei, B. Yang et al., Carbon-rich nonprecious metal single atom electrocatalysts for $\mathrm{CO}_{2}$ reduction and hydrogen evolution. Small Methods 3(10), 1900210 (2019). https://doi.org/10.1002/smtd.201900210

46. X. Wang, Q. Zhao, B. Yang, Z. Li, Z. Bo et al., Emerging nanostructured carbon-based non-precious metal electrocatalysts for selective electrochemical $\mathrm{CO}_{2}$ reduction to $\mathrm{CO}$. J. Mater. Chem. A 7(44), 25191-25202 (2019). https://doi. org/10.1039/c9ta09681g

47. T. Yao, X. An, H. Han, J.Q. Chen, C. Li, Photoelectrocatalytic materials for solar water splitting. Adv. Energy Mater. 8(21), 1800210 (2018). https://doi.org/10.1002/aenm.201800210

48. N. Guijarro, M.S. Prévot, K. Sivula, Surface modification of semiconductor photoelectrodes Phys. Chem. Chem. Phys. 17(24), 15655-15674 (2015). https://doi.org/10.1039/C5CP0 $1992 \mathrm{C}$

49. M.G. Kibria, S.Z. Zhao, F.A. Chowdhury, Q. Wang, H.P.T. Ngugyen et al., Tuning the surface Fermi level on p-type gallium nitride nanowires for efficient overall water splitting. Nat. Commun. 5, 3825 (2014). https://doi.org/10.1038/ ncomms 4825

50. Z. Zhang, J.T. Yates Jr., Band bending in semiconductors: chemical and physical consequences at surfaces and interfaces. Chem. Rev. 112(10), 5520-5551 (2012). https://doi. org/10.1021/cr3000626

51. N. Kaneza, P.S. Shinde, Y. Ma, S. Pan, Photoelectrochemical study of carbon-modified p-type $\mathrm{Cu}_{2} \mathrm{O}$ nanoneedles and n-type $\mathrm{TiO}_{2-x}$ nanorods for Z-scheme solar water splitting in a tandem cell configuration. RSC Adv. 9(24), 13576-13585 (2019). https://doi.org/10.1039/c8ra09403a

52. Z. Li, W. Wang, C. Ding, Z. Wang, S. Liao, C. Li, Biomimic electron transport via multi redox shuttles from photosystem II to photoelectrochemical cell for solar water splitting. Energy Environ. Sci. 10(3), 765-771 (2017). https://doi. org/10.1039/C6EE03401B

53. W. Wang, H. Wang, Q. Zhu, W. Qin, G. Han et al., Spatially separated photosystem II and a silicon photoelectrochemical cell for overall water splitting: a natural-artificial photosynthetic hybrid. Angew. Chem. Int. Ed. 55(32), 9229-9233 (2016). https://doi.org/10.1002/anie.201604091 
54. R. Abe, K. Sayama, H. Sugihara, Development of new photocatalytic water splitting into $\mathrm{H}_{2}$ and $\mathrm{O}_{2}$ using two different semiconductor photocatalysts and a shuttle redox mediator $\mathrm{IO}_{3}{ }^{-} / \mathrm{I}^{-}$. J. Phys. Chem. B 109(33), 16052-16061 (2005). https://doi.org/10.1021/jp0528481

55. J. Zhang, H. Li, J. Zhang, Y. Wu, Y. Geng et al., A promising anchor group for efficient organic dye sensitized solar cells with iodine-free redox shuttles: a theoretical evaluation. J. Mater. Chem. A 1(44), 14000 (2013). https://doi.org/10.1039/ c3ta12311a

56. Y. Kageshima, H. Kumagai, T. Minegishi, J. Kubota, K. Domen, A photoelectrochemical solar cell consisting of a cadmium sulfide photoanode and a Ruthenium-2,2'bipyridine redox shuttle in a non-aqueous electrolyte. Angew. Chem. Int. Ed. 54(27), 7877-7881 (2015). https:// doi.org/10.1002/anie.201502586

57. C.J. Gagliardi, A.K. Vannucci, J.J. Concepcion, Z. Chen, T.J. Meyer, The role of proton coupled electron transfer in water oxidation. Energy Environ. Sci. 5(7), 7704-7717 (2012). https://doi.org/10.1039/c2ee03311a

58. T.H. Han, Y.H. Kim, M.H. Kim, W. Song, T.W. Lee, Synergetic influences of mixed-host emitting layer structures and hole injection layers on efficiency and lifetime of simplified phosphorescent organic light-emitting diodes. ACS Appl. Mater. Interfaces. 8(9), 6152-6163 (2016). https://doi. org/10.1021/acsami.5b11791

59. K. Sivula, R. Zboril, F.L. Formal, R. Robert, A. Weidenkaff et al., Photoelectrochemical water splitting with mesoporous hematite prepared by a solution-based colloidal approach. J. Am. Chem. Soc. 132(21), 7436-7444 (2010). https://doi. org/10.1021/ja101564f

60. X.T. Xu, L. Pan, X. Zhang, L. Wang, J.J. Zou, Rational design and construction of cocatalysts for semiconductorbased photo-electrochemical oxygen evolution: a comprehensive review. Adv. Sci. 6(2), 1801505 (2019). https://doi. org/10.1002/advs.201801505

61. H. Zhou, Z. Wen, J. Liu, J. Ke, X. Duan et al., Z-scheme plasmonic Ag decorated $\mathrm{WO}_{3} / \mathrm{Bi}_{2} \mathrm{WO}_{6}$ hybrids for enhanced photocatalytic abatement of chlorinated-VOCs under solar light irradiation. Appl. Catal. B: Environ. 242, 76-84 (2019). https://doi.org/10.1016/j.apcatb.2018.09.090

62. T. Zhang, Y. Hou, V. Dzhagan, Z. Liao, G. Chai et al., Copper-surface-mediated synthesis of acetylenic carbon-rich nanofibers for active metal-free photocathodes. Nat. Commun. 9, 1140 (2018). https://doi.org/10.1038/s41467-01803444-0

63. Z. Zhang, S. Wang, M. Bao, J. Ren, S. Pei et al., Construction of ternary $\mathrm{Ag} / \mathrm{AgCl} / \mathrm{NH}_{2}-\mathrm{UiO}-66$ hybridized heterojunction for effective photocatalytic hexavalent chromium reduction. J. Colloid Interf. Sci. 555, 342-351 (2019). https://doi. org/10.1016/j.jcis.2019.07.103

64. X. Zou, Y. Dong, C. Yuan, H. Ge, J. Ke et al., $\mathrm{Zn}_{2} \mathrm{SnO}_{4}$ QDs decorated $\mathrm{Bi}_{2} \mathrm{WO}_{6}$ nanoplates for improved visible-lightdriven photocatalytic removal of gaseous contaminants. J. Taiwan Inst. Chem. Eng. 96, 390-399 (2019). https://doi. org/10.1016/j.jtice.2018.12.005
65. J. Liu, Y. Li, Z. Li, J. Ke, H. Xiao et al., In situ growing of $\mathrm{Bi} / \mathrm{Bi}_{2} \mathrm{O}_{2} \mathrm{CO}_{3}$ on $\mathrm{Bi}_{2} \mathrm{WO}_{6}$ nanosheets for improved photocatalytic performance. Catal. Today 314, 2-9 (2018). https://doi. org/10.1016/j.cattod.2017.12.001

66. J. Chen, X. Zhang, F. Bi, X. Zhang, Y. Yang et al., A facile synthesis for uniform tablet-like $\mathrm{TiO}_{2} / \mathrm{C}$ derived from Materials of Institut Lavoisier-125(Ti) (MIL-125(Ti)) and their enhanced visible light-driven photodegradation of tetracycline. J. Colloid Interf. Sci. 571, 275-284 (2020). https://doi. org/10.1016/j.jcis.2020.03.055

67. J. Zhu, S. Pang, T. Dittrich, Y. Gao, W. Nie et al., Visualizing the nano cocatalyst aligned electric fields on single photocatalyst particles. Nano Lett. 17(11), 6735-6741 (2017). https ://doi.org/10.1021/acs.nanolett.7b02799

68. X. Zhang, Y. Wang, F. Hou, H. Li, Y. Yang et al., Effects of Ag loading on structural and photocatalytic properties of flower-like ZnO microspheres. Appl. Surf. Sci. 391, 476-483 (2017). https://doi.org/10.1016/j.apsusc.2016.06.109

69. D. Yuan, C. Zhang, S. Tang, M. Sun, Y. Zhang et al., $\mathrm{Fe}^{3+}$-sulfite complexation enhanced persulfate Fenton-like process for antibiotic degradation based on response surface optimization. Sci. Total Environ. 727, 138773 (2020). https ://doi.org/10.1016/j.scitotenv.2020.138773

70. M.G. Ahmed, I.E. Kretschmer, T.A. Kandiel, A.Y. Ahmed, F.A. Rashwan et al., A facile surface passivation of hematite photoanodes with $\mathrm{TiO}_{2}$ overlayers for efficient solar water splitting. ACS Appl. Mater. Interfaces 7(43), 24053-24062 (2015). https://doi.org/10.1021/acsami.5b07065

71. K. Kim, J. Yang, J.H. Moon, Unveiling the effects of nanostructures and core materials on charge-transport dynamics in heterojunction electrodes for photoelectrochemical water splitting. ACS Appl. Mater. Interfaces 12(19), 21894-21902 (2020). https://doi.org/10.1021/acsami.0c03958

72. J.E. Thorne, J.W. Jang, E.Y. Liu, D. Wang, Understanding the origin of photoelectrode performance enhancement by probing surface kinetics. Chem. Sci. 7(5), 3347-3354 (2016). https://doi.org/10.1039/c5sc04519c

73. H. Zhang, W. Zhou, Y. Yang, C. Cheng, 3D $\mathrm{WO}_{3} / \mathrm{BiVO}_{4} /$ cobalt phosphate composites inverse opal photoanode for efficient photoelectrochemical water splitting. Small 13(16), 1603840 (2017). https://doi.org/10.1002/smll.201603840

74. I. Grigioni, M. Abdellah, A. Corti, M.V. Dozzi, L. Hammarstrom, E. Selli, Photoinduced charge-transfer dynamics in $\mathrm{WO}_{3} / \mathrm{BiVO}_{4}$ photoanodes probed through midinfrared transient absorption spectroscopy. J. Am. Chem. Soc. 140(43), 14042-14045 (2018). https://doi.org/10.1021/jacs.8b08309

75. T.-P. Ruoko, A. Hiltunen, T. Iivonen, R. Ulkuniemi, K. Lahtonen et al., Charge carrier dynamics in tantalum oxide overlayered and tantalum doped hematite photoanodes. J. Mater. Chem. A 7(7), 3206-3215 (2019). https://doi. org/10.1039/c8ta09501a

76. A. Yamakata, C.S.K. Ranasinghe, N. Hayashi, K. Kato, J.J.M. Vequizo, Identification of individual electron- and hole-transfer kinetics at $\mathrm{CoO}_{x} / \mathrm{BiVO}_{4} / \mathrm{SnO}_{2}$ double heterojunctions. ACS Appl. Energy Mater. 3(1), 1207-1214 (2019). https:// doi.org/10.1021/acsaem.9b02262 
77. Y.-C. Pu, W.-T. Chen, M.-J. Fang, Y.-L. Chen, K.-A. Tsai et al., $\mathrm{Au}-\mathrm{Cd}_{1-x} \mathrm{Zn}_{x} \mathrm{~S}$ core-alloyed shell nanocrystals: boosting the interfacial charge dynamics by adjusting the shell composition. J. Mater. Chem. A 6(36), 17503-17513 (2018). https://doi.org/10.1039/c8ta05539d

78. Y. Liu, H. Zhang, J. Ke, J. Zhang, W. Tian et al., OD $\left(\mathrm{MoS}_{2}\right) / 2 \mathrm{D}\left(\mathrm{g}-\mathrm{C}_{3} \mathrm{~N}_{4}\right)$ heterojunctions in $\mathrm{Z}$-scheme for enhanced photocatalytic and electrochemical hydrogen evolution. Appl. Catal. B: Environ. 228, 64-74 (2018). https:// doi.org/10.1016/j.apcatb.2018.01.067

79. X. Zhang, Y. Yang, W. Huang, Y. Yang, Y. Wang et al., g- $\mathrm{C}_{3} \mathrm{~N}_{4} / \mathrm{UiO}-66$ nanohybrids with enhanced photocatalytic activities for the oxidation of dye under visible light irradiation. Mater. Res. Bull. 99, 349-358 (2018). https://doi. org/10.1016/j.materresbull.2017.11.028

80. X. Zou, Y. Dong, S. Li, J. Ke, Y. Cui et al., Fabrication of $\mathrm{V}_{2} \mathrm{O}_{5} / g-\mathrm{C}_{3} \mathrm{~N}_{4}$ heterojunction composites and its enhanced visible light photocatalytic performance for degradation of gaseous ortho-dichlorobenzene. J. Taiwan Inst. Chem. Eng. 93, 158-165 (2018). https://doi.org/10.1016/j.jtice.2018.05.041

81. Q. Liu, T. Chen, Y. Guo, Z. Zhang, X. Fang, Ultrathin $g-\mathrm{C}_{3} \mathrm{~N}_{4}$ nanosheets coupled with carbon nanodots as $2 \mathrm{D} / 0 \mathrm{D}$ composites for efficient photocatalytic $\mathrm{H}_{2}$ evolution. Appl. Catal. B: Environ. 193, 248-258 (2016). https://doi.org/10.1016/j.apcat b.2016.04.034

82. M. Faraji, M. Yousefi, S. Yousefzadeh, M. Zirak, N. Naseri et al., Two-dimensional materials in semiconductor photoelectrocatalytic systems for water splitting. Energy Environ. Sci. 12(1), 59-95 (2019). https://doi.org/10.1039/c8ee00886h

83. G. Gao, Y. Jiao, F. Ma, Y. Jiao, E. Waclawik et al., Carbon nanodot decorated graphitic carbon nitride: new insights into the enhanced photocatalytic water splitting from ab initio studies. Phys. Chem. Chem. Phys. 17(46), 31140-31144 (2015). https://doi.org/10.1039/c5cp05512a

84. J. Liu, Y. Liu, N. Liu, Y. Han, X. Zhang et al., Metal-free efficient photocatalyst for stable visible water splitting via a two-electron pathway. Science 347(6225), 970-974 (2015). https://doi.org/10.1126/science.aaa3145

85. Y. Wei, Z. Wang, J. Su, L. Guo, Metal-free flexible protonated g- $\mathrm{C}_{3} \mathrm{~N}_{4}$ /carbon dots photoanode for photoelectrochemical water splitting. ChemElectroChem 5(19), 2734-2737 (2018). https://doi.org/10.1002/celc.201800550

86. G. Peng, M. Volokh, J. Tzadikov, J. Sun, M. Shalom, Carbonnitride/reduced graphene oxide film with enhanced electron diffusion length: an efficient photo-electrochemical cell for hydrogen generation. Adv. Energy Mater. 8(23), 1800566 (2018). https://doi.org/10.1002/aenm.201800566

87. X. Zhao, D. Pan, X. Chen, R. Li, T. Jiang et al., g- $\mathrm{C}_{3} \mathrm{~N}_{4}$ photoanode for photoelectrocatalytic synergistic pollutant degradation and hydrogen evolution. Appl. Surf. Sci. 467-468, 658665 (2019). https://doi.org/10.1016/j.apsusc.2018.10.090

88. Y. Hou, Z. Wen, S. Cui, X. Guo, J. Chen, Constructing 2D porous graphitic $\mathrm{C}_{3} \mathrm{~N}_{4}$ nanosheets/nitrogen-doped graphene/ layered $\mathrm{MoS}_{2}$ ternary nanojunction with enhanced photoelectrochemical activity. Adv. Mater. 25(43), 6291-6297 (2013). https://doi.org/10.1002/adma.201303116
89. X. Gao, Y. Zhu, D. Yi, J. Zhou, S. Zhang et al., Ultrathin graphdiyne film on graphene through solution-phase van der Waals epitaxy. Sci. Adv. 4(7), eaat6378 (2018). https://doi. org/10.1126/sciadv.aat6378

90. X. Gao, J. Li, R. Du, J. Zhou, M.Y. Huang et al., Direct synthesis of graphdiyne nanowalls on arbitrary substrates and its application for photoelectrochemical water splitting cell. Adv. Mater. 29(9), 1605308 (2017). https://doi.org/10.1002/ adma.201605308

91. J. Li, X. Gao, B. Liu, Q. Feng, X.B. Li et al., Graphdiyne: a metal-free material as hole transfer layer to fabricate quantum dot-sensitized photocathodes for hydrogen production. J. Am. Chem. Soc. 138(12), 3954-3957 (2016). https://doi. org/10.1021/jacs.5b12758

92. Y.Y. Han, X.L. Lu, S.F. Tang, X.P. Yin, Z.W. Wei et al., Metal-free 2D/2D heterojunction of graphitic carbon nitride/ graphdiyne for improving the hole mobility of graphitic carbon nitride. Adv. Energy Mater. 8(16), 1702992 (2018). https ://doi.org/10.1002/aenm.201702992

93. Q. Quan, T. Zhang, C. Lei, B. Yang, Z. Li et al., Confined carburization-engineered synthesis of ultrathin nickel oxide/ nickel heterostructured nanosheets for enhanced oxygen evolution reaction. Nanoscale 11(46), 22261-22269 (2019). https ://doi.org/10.1039/c9nr07986f

94. Y. Li, Y. Li, C.M. Araujo, W. Luo, R. Ahuja, Single-layer $\mathrm{MoS}_{2}$ as an efficient photocatalyst. Catal. Sci. Technol. 3(9), 2214-2220 (2013). https://doi.org/10.1039/c3cy00207a

95. Z. Chen, A.J. Forman, T.F. Jaramillo, Bridging the gap between bulk and nanostructured photoelectrodes: the impact of surface states on the electrocatalytic and photoelectrochemical properties of $\mathrm{MoS}_{2}$. J. Phys. Chem. C 117(19), 9713-9722 (2013). https://doi.org/10.1021/jp311375k

96. K. Chang, Z. Mei, T. Wang, Q. Kang, S. Ouyang et al., $\mathrm{MoS}_{2} /$ graphene cocatalyst for efficient photocatalytic $\mathrm{H}_{2}$ evolution under visible light irradiation. ACS Nano 8(7), 7078-7087 (2014). https://doi.org/10.1021/nn5019945

97. C. Guo, X. Tong, X. Guo, Solvothermal synthesis of $\mathrm{FeS}_{2}$ nanoparticles for photoelectrochemical hydrogen generation in neutral water. Mater. Lett. 161, 220-223 (2015). https:// doi.org/10.1016/j.matlet.2015.08.112

98. Y. Liu, H. Cheng, M. Lyu, S. Fan, Q. Liu et al., Low overpotential in vacancy-rich ultrathin $\mathrm{CoSe}_{2}$ nanosheets for water oxidation. J. Am. Chem. Soc. 136(44), 15670-15675 (2014). https://doi.org/10.1021/ja5085157

99. I.H. Kwak, H.S. Im, D.M. Jang, Y.W. Kim, K. Park et al., $\mathrm{CoSe}_{2}$ and $\mathrm{NiSe}_{2}$ nanocrystals as superior bifunctional catalysts for electrochemical and photoelectrochemical water splitting. ACS Appl. Mater. Interfaces 8(8), 5327-5334 (2016). https://doi.org/10.1021/acsami.5b12093

100. L. Wang, J. Cao, C. Lei, Q. Dai, B. Yang et al., Strongly coupled 3D N-doped $\mathrm{MoO}_{2} / \mathrm{Ni}_{3} \mathrm{~S}_{2}$ hybrid for high current density hydrogen evolution electrocatalysis and biomass upgrading. ACS Appl. Mater. Interfaces. 11(31), 27743-27750 (2019). https://doi.org/10.1021/acsami.9b06502

101. Y. Hou, M. Qiu, G. Nam, M.G. Kim, T. Zhang et al., Integrated hierarchical cobalt sulfide/nickel selenide hybrid 
nanosheets as an efficient three-dimensional electrode for electrochemical and photoelectrochemical water splitting. Nano Lett. 17(7), 4202-4209 (2017). https://doi.org/10.1021/ acs.nanolett. $7 \mathrm{~b} 01030$

102. Y. Li, J. Shi, Y. Mi, X. Sui, H. Xu et al., Ultrafast carrier dynamics in two-dimensional transition metal dichalcogenides. J. Mater. Chem. C 7(15), 4304-4319 (2019). https:// doi.org/10.1039/c8tc06343e

103. J. Ke, J. Liu, H. Sun, H. Zhang, X. Duan et al., Facile assembly of $\mathrm{Bi}_{2} \mathrm{O}_{3} / \mathrm{Bi}_{2} \mathrm{~S}_{3} / \mathrm{MoS}_{2} \mathrm{n}$-p heterojunction with layered $\mathrm{n}-\mathrm{Bi}_{2} \mathrm{O}_{3}$ and $\mathrm{p}-\mathrm{MoS}_{2}$ for enhanced photocatalytic water oxidation and pollutant degradation. Appl. Catal. B: Environ. 200, 47-55 (2017). https://doi.org/10.1016/j.apcatb.2016.06.071

104. N.N. Rosman, R.M. Yunus, L.J. Minggu, K. Arifin, M.N.I. Salehmin et al., Photocatalytic properties of two-dimensional graphene and layered transition-metal dichalcogenides based photocatalyst for photoelectrochemical hydrogen generation: an overview. Int. J. Hydrogen Energ. 43, 18925-18945 (2018). https://doi.org/10.1016/j.ijhydene.2018.08.126

105. F. Carraro, L. Calvillo, M. Cattelan, M. Favaro, M. Righetto et al., Fast one-pot synthesis of $\mathrm{MoS}_{2}$ /crumpled graphene p-n nanonjunctions for enhanced photoelectrochemical hydrogen production. ACS Appl. Mater. Interfaces 7(46), 25685-25692 (2015). https://doi.org/10.1021/acsami.5b06668

106. R. Ranjan, M. Kumar, A.S.K. Sinha, Development and characterization of $\mathrm{rGO}$ supported $\mathrm{CdS} / \mathrm{MoS}_{2}$ photoelectrochemical catalyst for splitting water by visible light. Int. J. Hydrogen Energ. 44(31), 16176-16189 (2019). https://doi. org/10.1016/j.ijhydene.2019.03.126

107. Y. Jiao, Q. Huang, J. Wang, Z. He, Z. Li, A novel $\mathrm{MoS}_{2}$ quantum dots (QDs) decorated Z-scheme $\mathrm{g}-\mathrm{C}_{3} \mathrm{~N}_{4}$ nanosheet/N doped carbon dots heterostructure photocatalyst for photocatalytic hydrogen evolution. Appl. Catal. B: Environ. 247, 124132 (2019). https://doi.org/10.1016/j.apcatb.2019.01.073

108. N. Li, Z. Liu, M. Liu, C. Xue, Q. Chang et al., Facile synthesis of carbon dots@2D $\mathrm{MoS}_{2}$ heterostructure with enhanced photocatalytic properties. Inorg. Chem. 58(9), 5746-5752 (2019). https://doi.org/10.1021/acs.inorgchem.9b00111

109. J. Zheng, R. Zhang, X. Wang, P. Yu, Importance of carbon quantum dots for improving the electrochemical performance of $\mathrm{MoS}_{2} @ \mathrm{ZnS}$ composite. J. Mater. Sci. 54, 13509-13522 (2019). https://doi.org/10.1007/s10853-019-03860-7

110. S. Zhao, C. Li, L. Wang, N. Liu, S. Qiao et al., Carbon quantum dots modified $\mathrm{MoS}_{2}$ with visible-light-induced high hydrogen evolution catalytic ability. Carbon 99, 599-606 (2016). https://doi.org/10.1016/j.carbon.2015.12.088

111. L. Hui, Y. Xue, F. He, D. Jia, Y. Li, Efficient hydrogen generation on graphdiyne-based heterostructure. Nano Energy 55, 135-142 (2019). https://doi.org/10.1016/j.nanoe n.2018.10.062

112. J. Pang, R.G. Mendes, A. Bachmatiuk, L. Zhao, H.Q. Ta et al., Applications of 2D MXenes in energy conversion and storage systems. Chem. Soc. Rev. 48(1), 72-133 (2019). https ://doi.org/10.1039/c8cs00324f

113. X. Zang, C. Jian, T. Zhu, Z. Fan, W. Wang et al., Lasersculptured ultrathin transition metal carbide layers for energy storage and energy harvesting applications. Nat. Commun. 10, 3112 (2019). https://doi.org/10.1038/s41467-019-10999-Z

114. H. Wang, Y. Sun, Y. Wu, W. Tu, S. Wu et al., Electrical promotion of spatially photoinduced charge separation via interfacial-built-in quasi-alloying effect in hierarchical $\mathrm{Zn}_{2} \mathrm{In}_{2} \mathrm{~S}_{5} /$ $\mathrm{Ti}_{3} \mathrm{C}_{2}(\mathrm{O}, \mathrm{OH})_{x}$ hybrids toward efficient photocatalytic hydrogen evolution and environmental remediation. Appl. Catal. B: Environ. 245, 290-301 (2019). https://doi.org/10.1016/j. apcatb.2018.12.051

115. J. Peng, X. Chen, W.-J. Ong, X. Zhao, N. Li, Surface and heterointerface engineering of 2D MXenes and their nanocomposites: insights into electro- and photocatalysis. Chem 5(1), 18-50 (2019). https://doi.org/10.1016/j.chempr.2018.08.037

116. T.A. Le, Q.V. Bui, N.Q. Tran, Y. Cho, Y. Hong et al., Synergistic effects of nitrogen doping on MXene for enhancement of hydrogen evolution reaction. ACS Sustainable Chem. Eng. 7(19), 16879-16888 (2019). https://doi.org/10.1021/acssu schemeng.9b04470

117. Y. Zhang, H. Jiang, Y. Lin, H. Liu, Q. He et al., In situ growth of cobalt nanoparticles encapsulated nitrogen-doped carbon nanotubes among $\mathrm{Ti}_{3} \mathrm{C}_{2} \mathrm{~T}_{x}$ (MXene) matrix for oxygen reduction and evolution. Adv. Mater. Interfaces 5(16), 1800392 (2018). https://doi.org/10.1002/admi.201800392

118. S. Zhou, X. Yang, W. Pei, N. Liu, J. Zhao, Heterostructures of MXenes and $\mathrm{N}$-doped graphene as highly active bifunctional electrocatalysts. Nanoscale 10(23), 10876-10883 (2018). https://doi.org/10.1039/c8nr01090k

119. X. Wu, Z. Wang, M. Yu, L. Xiu, J. Qiu, Stabilizing the MXenes by carbon nanoplating for developing hierarchical nanohybrids with efficient lithium storage and hydrogen evolution capability. Adv. Mater. 29(24), 1607017 (2017). https ://doi.org/10.1002/adma.201607017

120. J. Chen, X. Yuan, F. Lyu, Q. Zhong, H. Hu et al., Integrating MXene nanosheets with cobalt-tipped carbon nanotubes for an efficient oxygen reduction reaction. J. Mater. Chem. A 7(3), 1281-1286 (2019). https://doi.org/10.1039/c8ta10574j

121. R. Gao, D. Yan, Recent development of Ni/Fe-based micro/ nanostructures toward photo/electrochemical water oxidation. Adv. Energy Mater. 10(11), 1900954 (2019). https:// doi.org/10.1002/aenm.201900954

122. J. Mohammed-Ibrahim, A review on NiFe-based electrocatalysts for efficient alkaline oxygen evolution reaction. J. Power Sources 448, 227375 (2020). https://doi.org/10.1016/j.jpows our.2019.227375

123. W. Zhang, D. Li, L. Zhang, X. She, D. Yang, NiFe-based nanostructures on nickel foam as highly efficiently electrocatalysts for oxygen and hydrogen evolution reactions. J. Energy Chem. 39, 39-53 (2019). https://doi.org/10.1016/j. jechem.2019.01.017

124. S. Kment, F. Riboni, S. Pausova, L. Wang, L. Wang et al., Photoanodes based on $\mathrm{TiO}_{2}$ and $\alpha-\mathrm{Fe}_{2} \mathrm{O}_{3}$ for solar water splitting-superior role of 1D nanoarchitectures and of combined heterostructures. Chem. Soc. Rev. 46(12), 3716-3769 (2017). https://doi.org/10.1039/c6cs00015k

125. K. Sivula, F. Le Formal, M. Gratzel, Solar water splitting: progress using hematite alpha- $\mathrm{Fe}_{2} \mathrm{O}_{3}$ photoelectrodes. 
Chemsuschem 4(4), 432-449 (2011). https://doi.org/10.1002/ cssc. 201000416

126. J. Ke, H. Zhou, J. Liu, X. Duan, H. Zhang et al., Crystal transformation of 2D tungstic acid $\mathrm{H}_{2} \mathrm{WO}_{4}$ to $\mathrm{WO}_{3}$ for enhanced photocatalytic water oxidation. J. Colloid Interf. Sci. 514, 576-583 (2018). https://doi.org/10.1016/j.jcis.2017.12.066

127. X. Gao, H. Lv, Z. Li, Q. Xu, H. Liu et al., Low-cost and high-performance of a vertically grown 3D Ni-Fe layered double hydroxide/graphene aerogel supercapacitor electrode material. RSC Adv. 6(109), 107278-107285 (2016). https:// doi.org/10.1039/c6ra19495h

128. J. Huang, G. Hu, Y. Ding, M. Pang, B. Ma, Mn-doping and $\mathrm{NiFe}$ layered double hydroxide coating: effective approaches to enhancing the performance of $\alpha-\mathrm{Fe}_{2} \mathrm{O}_{3}$ in photoelectrochemical water oxidation. J. Catal. 340, 261-269 (2016). https://doi.org/10.1016/j.jcat.2016.05.007

129. R. Zhang, M. Shao, S. Xu, F. Ning, L. Zhou et al., Photoassisted synthesis of zinc-iron layered double hydroxides/ $\mathrm{TiO}_{2}$ nanoarrays toward highly-efficient photoelectrochemical water splitting. Nano Energy 33, 21-28 (2017). https:// doi.org/10.1016/j.nanoen.2017.01.020

130. S.O. Ganiyu, T.X.H. Le, M. Bechelany, G. Esposito, E.D. van Hullebusch et al., A hierarchical CoFe-layered double hydroxide modified carbon-felt cathode for heterogeneous electro-Fenton process. J. Mater. Chem. A 5(7), 3655-3666 (2017). https://doi.org/10.1039/c6ta09100h

131. Y. Tang, R. Wang, Y. Yang, D. Yan, X. Xiang, Highly enhanced photoelectrochemical water oxidation efficiency based on triadic quantum dot/layered double hydroxide/ $\mathrm{BiVO}_{4}$ photoanodes. ACS Appl. Mater. Interfaces. 8(30), 19446-19455 (2016). https://doi.org/10.1021/acsami.6b049 37

132. Y. Zhao, B. Li, Q. Wang, W. Gao, C.J. Wang et al., NiTi-layered double hydroxides nanosheets as efficient photocatalysts for oxygen evolution from water using visible light. Chem. Sci. 5(3), 951-958 (2014). https://doi.org/10.1039/c3sc5 $2546 \mathrm{e}$

133. R. Boppella, C.H. Choi, J. Moon, D.H. Kim, Spatial charge separation on strongly coupled 2D-hybrid of $\mathrm{rGO} / \mathrm{La}_{2} \mathrm{Ti}_{2} \mathrm{O}_{7} /$ $\mathrm{NiFe}-\mathrm{LDH}$ heterostructures for highly efficient noble metal free photocatalytic hydrogen generation. Appl. Catal. B: Environ. 239, 178-186 (2018). https://doi.org/10.1016/j.apcat b.2018.07.063

134. L. Mohapatra, K. Parida, A review on the recent progress, challenges and perspective of layered double hydroxides as promising photocatalysts. J. Mater. Chem. A 4(28), 1074410766 (2016). https://doi.org/10.1039/c6ta01668e

135. M. Shao, F. Ning, M. Wei, D.G. Evans, X. Duan, Hierarchical nanowire arrays based on $\mathrm{ZnO}$ core-layered double hydroxide shell for largely enhanced photoelectrochemical water splitting. Adv. Funct. Mater. 24(5), 580-586 (2014). https://doi. org/10.1002/adfm.201301889

136. Q. Wang, D. O'Hare, Recent advances in the synthesis and application of layered double hydroxide (LDH) nanosheets. Chem. Rev. 112(7), 4124-4155 (2012). https://doi. org/10.1021/cr200434v
137. L. Ren, C. Wang, W. Li, R. Dong, H. Sun et al., Heterostructural NiFe-LDH@ $\mathrm{Ni}_{3} \mathrm{~S}_{2}$ nanosheet arrays as an efficient electrocatalyst for overall water splitting. Electrochim. Acta 318, 42-50 (2019). https://doi.org/10.1016/j.electacta.2019.06.060

138. P.F. Liu, S. Yang, B. Zhang, H.G. Yang, Defect-rich ultrathin cobalt-iron layered double hydroxide for electrochemical overall water splitting. ACS Appl. Mater. Interfaces 8(50), 34474-34481 (2016). https://doi.org/10.1021/acsami.6b128 03

139. Z. Liu, R. Ma, M. Osada, N. Iyi, Y. Ebina et al., Synthesis, anion exchange, and delamination of $\mathrm{Co}-\mathrm{Al}$ layered double hydroxide: assembly of the exfoliated nanosheet/polyanion composite films and magneto-optical studies. J. Am. Chem. Soc. 128(14), 4872-4880 (2006). https://doi.org/10.1021/ ja0584471

140. H. Chen, Q. Zhao, L. Gao, J. Ran, Y. Hou, Water-plasma assisted synthesis of oxygen-enriched $\mathrm{Ni}-\mathrm{Fe}$ layered double hydroxide nanosheets for efficient oxygen evolution reaction. ACS Sustainable Chem. Eng. 7(4), 4247-4254 (2019). https ://doi.org/10.1021/acssuschemeng.8b05953

141. L. Lv, Z. Yang, K. Chen, C. Wang, Y. Xiong, 2D layered double hydroxides for oxygen evolution reaction: from fundamental design to application. Adv. Energy Mater. 9(17), 1803358 (2019). https://doi.org/10.1002/aenm.201803358

142. K. He, T. Tadesse Tsega, X. Liu, J. Zai, X.H. Li et al., Utilizing the space-charge region of the FeNi-LDH/CoP p-n junction to promote performance in oxygen evolution electrocatalysis. Angew. Chem. Int. Ed. 58(34), 11903-11909 (2019). https://doi.org/10.1002/anie.201905281

143. X. Long, J. Li, S. Xiao, K. Yan, Z. Wang et al., A strongly coupled graphene and FeNi double hydroxide hybrid as an excellent electrocatalyst for the oxygen evolution reaction. Angew. Chem. Int. Ed. 53(29), 7584-7588 (2014). https:// doi.org/10.1002/anie.201402822

144. Z. Zhang, D. Zhou, J. Liao, X. Bao, H. Yu, Synthesis of high crystalline nickel-iron hydrotalcite-like compound as an efficient electrocatalyst for oxygen evolution reaction. Int. J. Energ. Res. 43(4), 1460-1467 (2019). https://doi. org/10.1002/er.4359

145. S. Samuei, Z. Rezvani, B. Habibi, M.S. Oskoui, Synthesis and characterization of oxidized CoMnAl-layered double hydroxide and graphene oxide nanocomposite as a more efficient electrocatalyst for oxygen evolution reaction. Appl. Clay Sci. 169, 31-39 (2019). https://doi.org/10.1016/j.clay.2018.12.008

146. X. Han, N. Suo, C. Chen, Z. Lin, Z. Dou et al., Graphene oxide guiding the constructing of nickel-iron layered double hydroxides arrays as a desirable bifunctional electrocatalyst for HER and OER. Int. J. Hydrog. Energy 44(57), 2987629888 (2019). https://doi.org/10.1016/j.ijhydene.2019.09.116

147. M. Gong, Y. Li, H. Wang, Y. Liang, J.Z. Wu et al., An advanced $\mathrm{Ni}-\mathrm{Fe}$ layered double hydroxide electrocatalyst for water oxidation. J. Am. Chem. Soc. 135(23), 8452-8455 (2013). https://doi.org/10.1021/ja4027715

148. D. Tang, Y. Han, W. Ji, S. Qiao, X. Zhou et al., A highperformance reduced graphene oxide/ZnCo layered double hydroxide electrocatalyst for efficient water oxidation. Dalton 
Trans. 43(40), 15119-15125 (2014). https://doi.org/10.1039/ c4dt01924e

149. D.H. Youn, Y.B. Park, J.Y. Kim, G. Magesh, Y.J. Jang et al., One-pot synthesis of NiFe layered double hydroxide/ reduced graphene oxide composite as an efficient electrocatalyst for electrochemical and photoelectrochemical water oxidation. J. Power Sources 294, 437-443 (2015). https://doi. org/10.1016/j.jpowsour.2015.06.098

150. Y. Hou, Z. Wen, S. Cui, X. Feng, J. Chen, Strongly coupled ternary hybrid aerogels of $\mathrm{N}$-deficient porous graphitic- $\mathrm{C}_{3} \mathrm{~N}_{4}$ nanosheets/N-doped graphene/NiFe-layered double hydroxide for solar-driven photoelectrochemical water oxidation. Nano Lett. 16(4), 2268-2277 (2016). https://doi.org/10.1021/ acs.nanolett.5b04496

151. J. Li, X. Gao, Z. Li, J.H. Wang, L. Zhu et al., Superhydrophilic graphdiyne accelerates interfacial mass/electron transportation to boost electrocatalytic and photoelectrocatalytic water oxidation activity. Adv. Funct. Mater. 29(16), 1808079 (2019). https://doi.org/10.1002/adfm.201808079

152. L. Sun, J. Sun, X. Yang, S. Bai, Y. Feng et al., An integrating photoanode consisting of $\mathrm{BiVO}_{4}, \mathrm{rGO}$ and $\mathrm{LDH}$ for photoelectrochemical water splitting. Dalton Trans. 48(42), 16091-16098 (2019). https://doi.org/10.1039/c9dt01819k

153. H. Qi, J. Wolfe, D. Fichou, Z. Chen, $\mathrm{Cu}_{2} \mathrm{O}$ photocathode for low bias photoelectrochemical water splitting enabled by $\mathrm{NiFe}$-layered double hydroxide co-catalyst. Sci. Rep. 6, 30882 (2016). https://doi.org/10.1038/srep30882

154. Y. Huang, Y. Yu, Y. Xin, N. Meng, Y. Yu et al., Promoting charge carrier utilization by integrating layered double hydroxide nanosheet arrays with porous $\mathrm{BiVO}_{4}$ photoanode for efficient photoelectrochemical water splitting. Sci. China Mater. 60(3), 193-207 (2017). https://doi.org/10.1007/s40843-016-5168-0

155. J. Liu, J. Ke, Y. Li, B. Liu, L. Wang et al., $\mathrm{Co}_{3} \mathrm{O}_{4}$ quantum dots $/ \mathrm{TiO}_{2}$ nanobelt hybrids for highly efficient photocatalytic overall water splitting. Appl. Catal. B: Environ. 236, 396-403 (2018). https://doi.org/10.1016/j.apcatb.2018.05.042

156. F. Ning, M. Shao, S. Xu, Y. Fu, R. Zhang et al., TiO 2 /graphene/NiFe-layered double hydroxide nanorod array photoanodes for efficient photoelectrochemical water splitting. Energy Environ. Sci. 9(8), 2633-2643 (2016). https://doi. org/10.1039/c6ee01092j

157. X. Zhang, R. Wang, F. Li, Z. An, M. Pu et al., Enhancing photoelectrochemical water oxidation efficiency of $\mathrm{BiVO}_{4}$ photoanodes by a hybrid structure of layered double hydroxide and graphene. Ind. Eng. Chem. Res. 56(38), 10711-10719 (2017). https://doi.org/10.1021/acs.iecr.7b02960

158. X. Lv, X. Xiao, M. Cao, Y. Bu, C. Wang et al., Efficient carbon dots $/ \mathrm{NiFe}$-layered double hydroxide $/ \mathrm{BiVO}_{4}$ photoanodes for photoelectrochemical water splitting. Appl. Surf. Sci. 439, 1065-1071 (2018). https://doi.org/10.1016/j.apsus c. 2017.12 .182

159. Y. Hou, F. Zuo, A. Dagg, P. Feng, Visible light-driven $\alpha-\mathrm{Fe}_{2} \mathrm{O}_{3}$ nanorod/graphene/ $\mathrm{BiV}_{1-x} \mathrm{Mo}_{x} \mathrm{O}_{4}$ core/shell heterojunction array for efficient photoelectrochemical water splitting. Nano Lett. 12(12), 6464-6473 (2012). https://doi. org/10.1021/nl303961c
160. D. Li, Z. Xing, X. Yu, X. Cheng, One-step hydrothermal synthesis of C-N-S-tridoped $\mathrm{TiO}_{2}$-based nanosheets photoelectrode for enhanced photoelectrocatalytic performance and mechanism. Electrochim. Acta 170, 182-190 (2015). https:// doi.org/10.1016/j.electacta.2015.04.148

161. Z. Kang, H. Si, S. Zhang, J. Wu, Y. Sun et al., Interface engineering for modulation of charge carrier behavior in $\mathrm{ZnO}$ photoelectrochemical water splitting. Adv. Funct. Mater. 29(15), 1808032 (2019). https://doi.org/10.1002/adfm.20180 8032

162. J. Ke, H. Zhou, J. Liu, Z. Zhang, X. Duan et al., Enhanced light-driven water splitting by fast electron transfer in $2 \mathrm{D} / 2 \mathrm{D}$ reduced graphene oxide/tungsten trioxide heterojunction with preferential facets. J. Colloid Interf. Sci. 555, 413-422 (2019). https://doi.org/10.1016/j.jcis.2019.08.008

163. Y. Hou, F. Zuo, A.P. Dagg, J. Liu, P. Feng, Branched $\mathrm{WO}_{3}$ nanosheet array with layered $\mathrm{C}_{3} \mathrm{~N}_{4}$ heterojunctions and $\mathrm{CoO}_{x}$ nanoparticles as a flexible photoanode for efficient photoelectrochemical water oxidation. Adv. Mater. 26(29), 5043-5049 (2014). https://doi.org/10.1002/adma.201401032

164. A. Saad, H. Shen, Z. Cheng, R. Arbi, B. Guo et al., Mesoporous ternary nitrides of earth-abundant metals as oxygen evolution electrocatalyst. Nano-Micro Lett. 12, 79 (2020). https://doi.org/10.1007/s40820-020-0412-8

165. J. Liu, J. Zhang, D. Wang, D. Li, J. Ke et al., Highly dispersed $\mathrm{NiCo}_{2} \mathrm{O}_{4}$ nanodots decorated three-dimensional g- $\mathrm{C}_{3} \mathrm{~N}_{4}$ for enhanced photocatalytic $\mathrm{H}_{2}$ generation. ACS Sustainable Chem. Eng. 7(14), 12428-12438 (2019). https://doi. org/10.1021/acssuschemeng.9b01965

166. J.H. Kim, J.S. Lee, Elaborately modified $\mathrm{BiVO}_{4}$ photoanodes for solar water splitting. Adv. Mater. 31(20), 1806938 (2019). https://doi.org/10.1002/adma.201806938

167. M. García-Tecedor, D. Cardenas-Morcoso, R. FernándezCliment, S. Giménez, The role of underlayers and overlayers in thin film $\mathrm{BiVO}_{4}$ photoanodes for solar water splitting. Adv. Mater. Interfaces 6(15), 1900299 (2019). https://doi. org/10.1002/admi.201900299

168. M. Tayebi, B.-K. Lee, Recent advances in $\mathrm{BiVO}_{4}$ semiconductor materials for hydrogen production using photoelectrochemical water splitting. Renew. Sust. Energ. Rev. 111, 332-343 (2019). https://doi.org/10.1016/j.rser.2019.05.030

169. K. Sharma, V. Dutta, S. Sharma, P. Raizada, A. HosseiniBandegharaei et al., Recent advances in enhanced photocatalytic activity of bismuth oxyhalides for efficient photocatalysis of organic pollutants in water: a review. J. Ind. Eng. Chem. 78, 1-20 (2019). https://doi.org/10.1016/j.jiec.2019.06.022

170. X. Jin, L. Ye, H. Xie, G. Chen, Bismuth-rich bismuth oxyhalides for environmental and energy photocatalysis. Coordin. Chem. Rev. 349, 84-101 (2017). https://doi.org/10.1016/j. ccr.2017.08.010

171. Y. Long, Q. Han, Z. Yang, Y. Ai, S. Sun et al., A novel solvent-free strategy for the synthesis of bismuth oxyhalides. J. Mater. Chem. A 6(27), 13005-13011 (2018). https://doi. org/10.1039/c8ta04529a

172. J. Li, H. Li, G. Zhan, L. Zhang, Solar water splitting and nitrogen fixation with layered bismuth oxyhalides. Acc. 
Chem. Res. 50(1), 112-121 (2017). https://doi.org/10.1021/ acs.accounts.6b00523

173. D.S. Bhachu, S.J.A. Moniz, S. Sathasivam, D.O. Scanlon, A. Walsh et al., Bismuth oxyhalides: synthesis, structure and photoelectrochemical activity. Chem. Sci. 7(8), 4832-4841 (2016). https://doi.org/10.1039/c6sc00389c

174. X. Wu, Y.H. Ng, L. Wang, Y. Du, S.X. Dou et al., Improving the photo-oxidative capability of $\mathrm{BiOBr}$ via crystal facet engineering. J. Mater. Chem. A 5(17), 8117-8124 (2017). https://doi.org/10.1039/c6ta10964k

175. K. Zhao, X. Zhang, L. Zhang, The first BiOI-based solar cells. Electrochem. Commun. 11(3), 612-615 (2009). https ://doi.org/10.1016/j.elecom.2008.12.041

176. Y. Ye, G. Gu, X. Wang, T. Ouyang, Y. Chen et al., 3D cross-linked $\mathrm{BiOI}$ decorated $\mathrm{ZnO} / \mathrm{CdS}$ nanorod arrays: a cost-effective hydrogen evolution photoanode with high photoelectrocatalytic activity. Int. J. Hydrogen Energ. 44(39), 21865-21872 (2019). https://doi.org/10.1016/j.ijhyd ene.2019.06.059

177. P.J. Mafa, A.T. Kuvarega, B.B. Mamba, B. Ntsendwana, Photoelectrocatalytic degradation of sulfamethoxazole on g- $\mathrm{C}_{3} \mathrm{~N}_{4} / \mathrm{BiOI} / \mathrm{EG} \mathrm{p}-\mathrm{n}$ heterojunction photoanode under visible light irradiation. Appl. Surf. Sci. 483, 506-520 (2019). https://doi.org/10.1016/j.apsusc.2019.03.281

178. Y. Bai, T. Chen, P. Wang, L. Wang, L. Ye, Bismuth-rich $\mathrm{Bi} 4 \mathrm{O} 5 \mathrm{X} 2(\mathrm{X}=\mathrm{Br}$, and $\mathrm{I})$ nanosheets with dominant 1001 facets exposure for photocatalytic $\mathrm{H} 2$ evolution. Chem. Eng. J. 304, 454-460 (2016). https://doi.org/10.1016/j. cej.2016.06.100

179. M. Wang, Q. Wang, J. Li, H. Zhang, W. Zhang et al., Assembly of large-area reduced graphene oxide films for the construction of Z-scheme over single-crystal porous $\mathrm{Bi}_{5} \mathrm{O}_{7} \mathrm{I}$ nanosheets. J. Colloid Interf. Sci. 552, 651-658 (2019). https ://doi.org/10.1016/j.jcis.2019.05.107

180. Q. Wang, Z. Liu, D. Liu, G. Liu, M. Yang et al., Ultrathin two-dimensional $\mathrm{BiOBr}_{x} \mathrm{I}_{1-x}$ solid solution with rich oxygen vacancies for enhanced visible-light-driven photoactivity in environmental remediation. Appl. Catal. B: Environ. 236, 222-232 (2018). https://doi.org/10.1016/j.apcat b.2018.05.029

181. T. Li, X. Zhang, C. Zhang, R. Li, J. Liu et al., Theoretical insights into photo-induced electron transfer at $\mathrm{BiOX}(\mathrm{X}=\mathrm{F}$, $\mathrm{Cl}, \mathrm{Br}, \mathrm{I})$ (001) surfaces and interfaces. Phys. Chem. Chem. Phys. 21(2), 868-875 (2019). https://doi.org/10.1039/c8cp0 $5671 \mathrm{~d}$

182. J. Di, J. Xia, M. Ji, B. Wang, S. Yin et al., Carbon quantum dots induced ultrasmall $\mathrm{BiOI}$ nanosheets with assembled hollow structures for broad spectrum photocatalytic activity and mechanism insight. Langmuir 32(8), 2075-2084 (2016). https ://doi.org/10.1021/acs.langmuir.5b04308

183. W. Sun, X. Wang, J. Feng, T. Li, Y. Huan et al., Controlled synthesis of $2 \mathrm{D} \mathrm{Mo}_{2}$ Cgraphene heterostructure on liquid $\mathrm{Au}$ substrates as enhanced electrocatalytic electrodes. Nanotechnology 30(38), 385601 (2019). https://doi.org/10.1088/1361$6528 / \mathrm{ab} 2 \mathrm{c} 0 \mathrm{~d}$

184. W.J. Ong, L.L. Tan, Y.H. Ng, S.T. Yong, S.P. Chai, Graphitic carbon nitride $\left(\mathrm{g}-\mathrm{C}_{3} \mathrm{~N}_{4}\right)$-based photocatalysts for artificial photosynthesis and environmental remediation: are we a step closer to achieving sustainability. Chem. Rev. 116(12), 71597329 (2016). https://doi.org/10.1021/acs.chemrev.6b00075

185. T. Li, H. Miras, Y. Song, Polyoxometalate (POM)-layered double hydroxides (LDH) composite materials: design and catalytic applications. Catalysts 7(9), 260 (2017). https://doi. org/10.3390/catal7090260

186. Z. Yu, L. Tetard, L. Zhai, J. Thomas, Supercapacitor electrode materials: nanostructures from 0 to 3 dimensions. Energy Environ. Sci. 8(3), 702-730 (2015). https://doi.org/10.1039/ c4ee03229b

187. H. Terrones, F. Lopez-Urias, M. Terrones, Novel hetero-layered materials with tunable direct band gaps by sandwiching different metal disulfides and diselenides. Sci. Rep. 3, 1549 (2013). https://doi.org/10.1038/srep01549 